Supporting Information

\title{
Effect of Copper Substrate Surface Orientation on the Reductive
}

\section{Functionalization of Graphene}

Xu Zhang* ${ }^{*}{ }^{\dagger}, \square$, Da Luo ${ }^{\dagger}$, Hanyang Zhang ${ }^{\dagger}$, Dae Yeon Hwang ${ }^{\perp}$, Sung O Park ${ }^{\perp}$, Bao-Wen Li ${ }^{\dagger}$,

Mandakini Biswal ${ }^{\dagger}$, Yi Jiang ${ }^{\dagger}$, Yuan Huang ${ }^{\dagger}$, Sang Kyu Kwak ${ }^{\dagger}$, , \#, Christopher W.

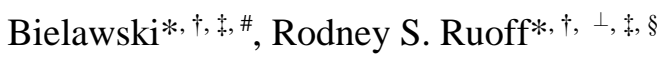

${ }^{\dagger}$ Center for Multidimensional Carbon Materials (CMCM), Institute for Basic Science (IBS),

Ulsan 44919, Republic of Korea

${ }^{\perp}$ School of Energy and Chemical Engineering, Ulsan National Institute of Science and Technology (UNIST), Ulsan 44919, Republic of Korea

${ }^{\ddagger}$ Department of Chemistry, UNIST, Ulsan 44919, Republic of Korea

${ }^{\S}$ School of Materials Science and Engineering, UNIST, Ulsan 44919, Republic of Korea

${ }^{\#}$ Department of Energy Engineering, UNIST, Ulsan 44919, Republic of Korea

*Corresponding author 
Table S1. Raman parameters of 1L graphene on different substrates (indicated).

\begin{tabular}{|c|c|c|c|c|}
\hline Substrate & $\omega_{\mathrm{G}} / \mathrm{cm}^{-1}$ & $\omega_{2 \mathrm{D}} / \mathbf{c m}^{-1}$ & $\mathrm{FWHM}_{\mathrm{G}} / \mathrm{cm}^{-1}$ & $\mathrm{FWHM}_{2 \mathrm{D}} / \mathrm{cm}^{-1}$ \\
\hline $\mathrm{Cu}(111)$ & 1596.5 & 2736.8 & 21.2 & 49.1 \\
\hline $\mathrm{Cu}(100)$ & 1587.4 & 2718.4 & 21.8 & 39.3 \\
\hline$p-\mathrm{Cu}$ & 1584.9 & 2712.4 & 20.7 & 29.7 \\
\hline $\mathrm{SiO}_{2}$ & 1582.9 & 2693.0 & 15.5 & 25.0 \\
\hline
\end{tabular}



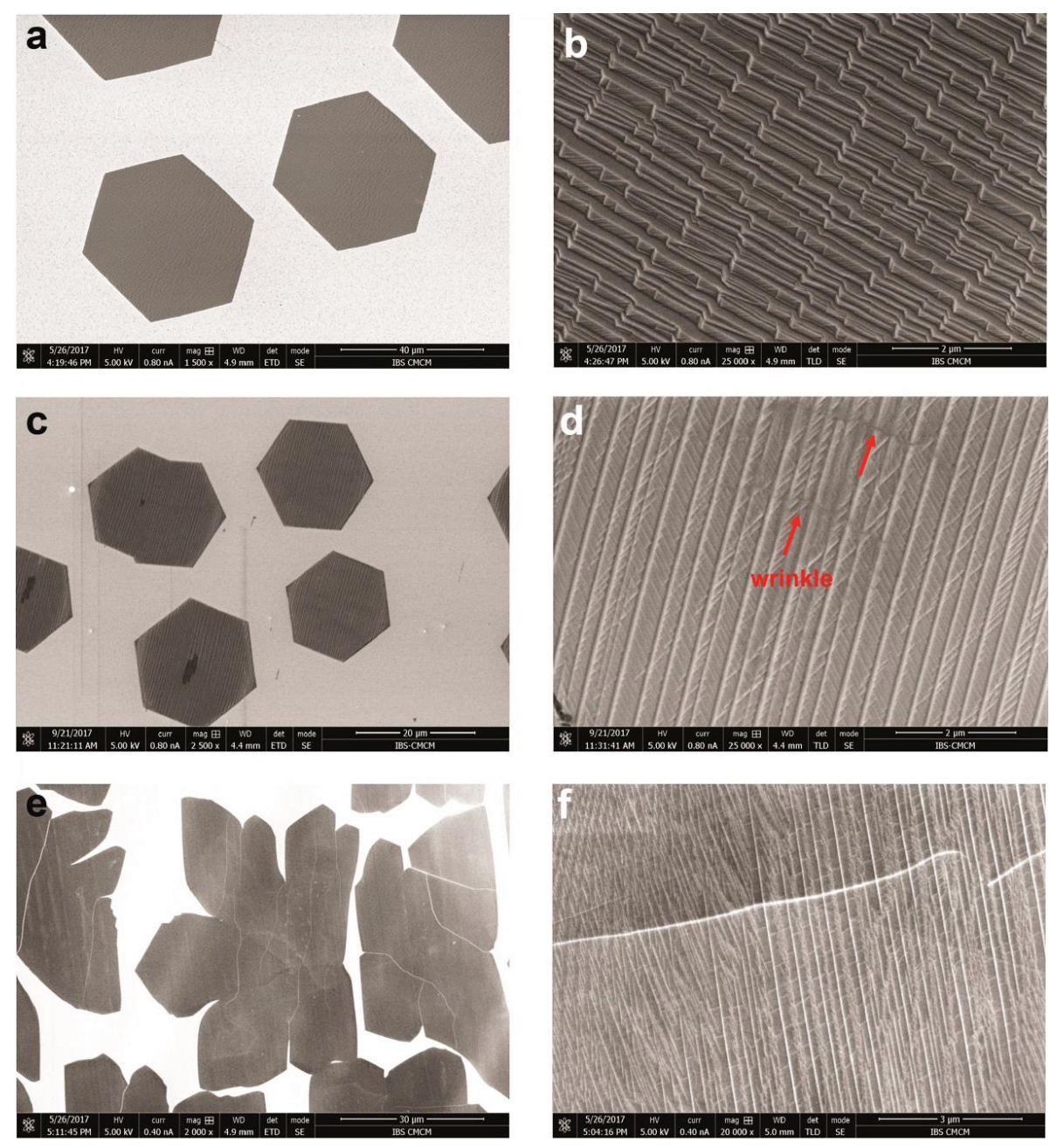

Figure S1. SEM images of 1L graphene islands on (a, b) $\mathrm{Cu}(111),(\mathrm{c}, \mathrm{d}) \mathrm{Cu}(100)$, and (e, f) $p$ $\mathrm{Cu}$.

The morphology of the graphene islands was examined by scanning electron microscopy (SEM). The SEM image in Figure S1a shows uniform single layer graphene (1L) islands with regular hexagonal shapes on $\mathrm{Cu}(111)$. All hexagons are in the same orientation as a result of epitaxial growth on the $\mathrm{Cu}(111)$ substrate; these hexagonal islands are most likely single crystal graphene. The magnified SEM image in Figure S1b shows that the underlying $\mathrm{Cu}(111)$ substrate has regular step-like features. We note that the graphene region always shows the presence of these steps compared to the 
relatively smooth bare $\mathrm{Cu}$ regions. We attribute this morphology to step bunching where smaller steps join to form a large step" during graphene growth. ${ }^{1}$ No cracks or wrinkles can be observed in this island and on most other islands. Figure S1c shows hexagonal graphene islands grown on $\mathrm{Cu}(100)$, which are less uniform in orientation and in the number of layers. Wrinkles can be observed in such graphene, as shown in Figure $\mathrm{S} 1 \mathrm{~d}$. Figure $\mathrm{S} 1 \mathrm{e}$ shows islands on polycrystalline $\mathrm{Cu}(p-\mathrm{Cu})$, which have irregular shapes due to non-epitaxial growth. The white lines suggest the formation of cracks during post-CVD cooling. The underlying $\mathrm{Cu}$ substrate has an irregular step feature (Figure S1f). The cracks formed on graphene expose 'new' edges with a higher reactivity than the interior region. 


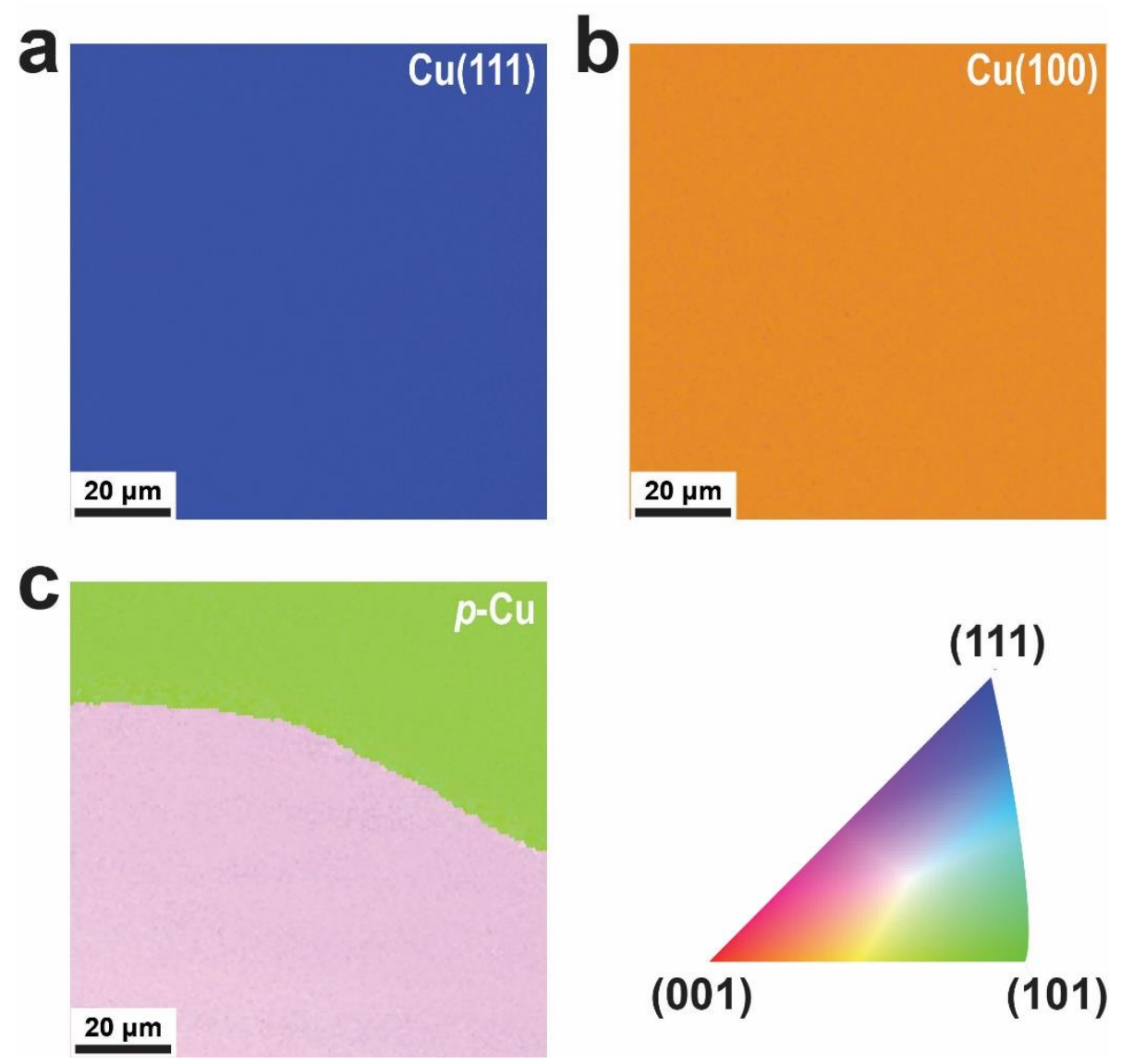

Figure S2. Identification of the surface orientations of $\mathrm{Cu}$ substrates underlying the graphene after CVD growth, by EBSD. (a) $\mathrm{Cu}(111)$, (b) $\mathrm{Cu}(100)$ and (c) $p-\mathrm{Cu}$.

The $\mathrm{Cu}$ surface lattice orientations after graphene growth were examined by electron backscatter diffraction (EBSD). Figure S2a shows a representative EBSD image of a 1L graphene island on $\mathrm{Cu}$ with a perfect (111) orientation (typical of all positions). The representative EBSD image of a 1L island on $\mathrm{Cu}$ in Figure S2b (typical of all positions) suggests a $\mathrm{Cu}$ surface orientation very close to $\mathrm{Cu}(100)$. For simplification, we use the term $\mathrm{Cu}(100)$ to designate this type of $\mathrm{Cu}$ substrate in this study. Figure S2c shows an EBSD image of a $1 \mathrm{~L}$ island on $p$-Cu acquired at the boundary between two $\mathrm{Cu}$ grains with different orientations. Many other $\mathrm{Cu}$ orientations can also be observed for this 
type of $\mathrm{Cu}$ substrate. In addition, graphene islands on most $p$-Cu grains have similar shapes and Raman spectra. Therefore, the selected $1 \mathrm{~L}$ island on $p-\mathrm{Cu}$ is representative of the majority of islands on $p-\mathrm{Cu}$.
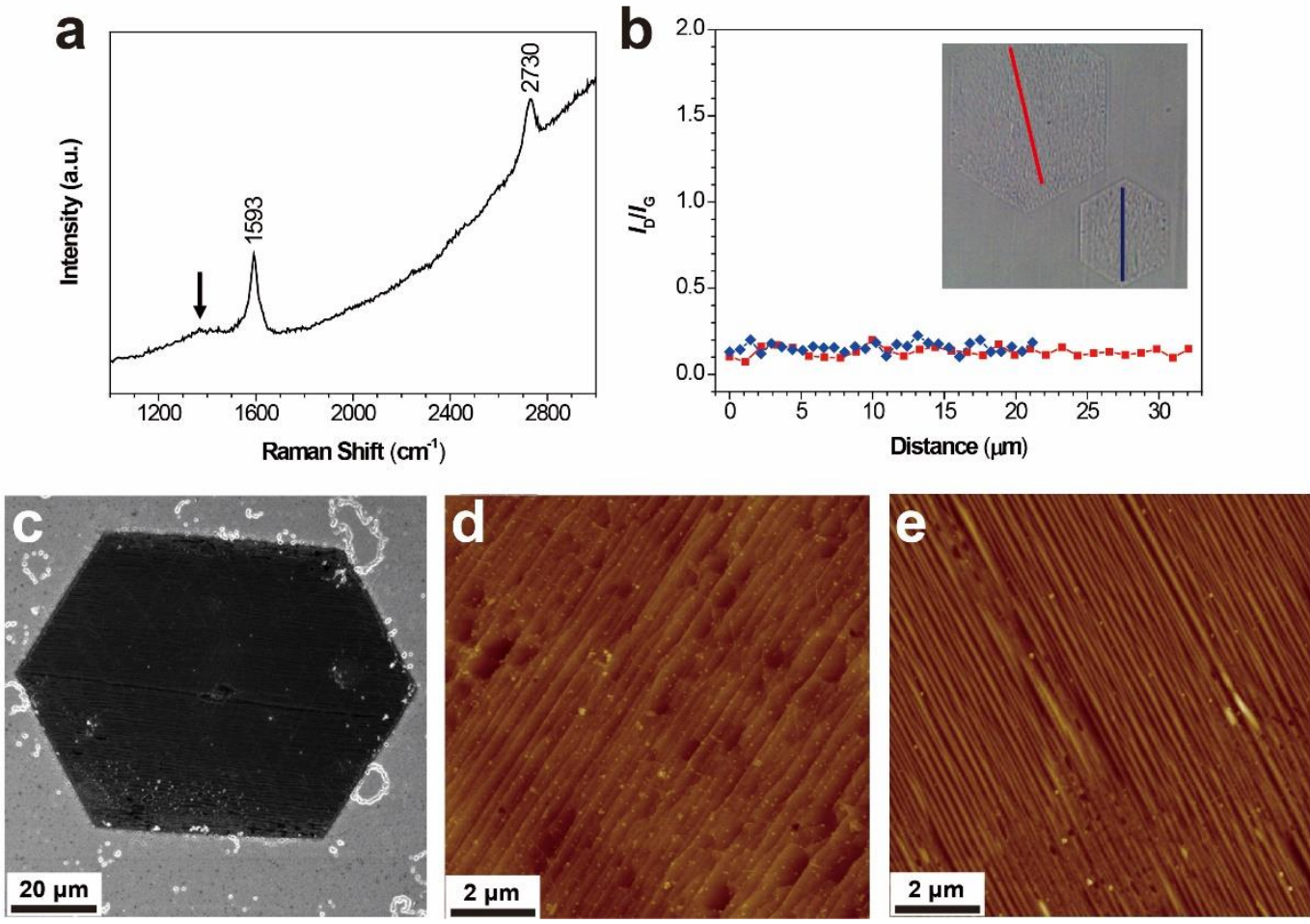

Figure S3. (a) Raman spectrum of a functionalized 1L graphene island on $\mathrm{Cu}(111)$ after heating at $450{ }^{\circ} \mathrm{C}$ for $2 \mathrm{~h}$. (b) Line scan $I_{\mathrm{D}} / I_{\mathrm{G}}$ ratios recorded from the heated sample. The inset optical image shows the scanned lines of two islands. (c) SEM image and (d, e) AFM image of functionalized 1L graphene islands on $\mathrm{Cu}(111)$ after heating at $450{ }^{\circ} \mathrm{C}$ for $2 \mathrm{~h}$.

A functionalized $1 \mathrm{~L}$ island on $\mathrm{Cu}(111)$ was heated at $450^{\circ} \mathrm{C}$ under an argon atmosphere $\left(3 \times 10^{-1}\right.$ Torr) for $2 \mathrm{~h}$. The strong D peak observed in the functionalized graphene (Figure 1c) is no longer observed in Figure S3a. Instead, a broad peak appears in the range $1100-1400 \mathrm{~cm}^{-1}$, which is attributed to the D peak of amorphous carbon formed 
by the carbonization of hydrocarbons on graphene. ${ }^{2}$ The asymmetric shape of the $G$ peak also indicates the contribution from amorphous carbon to the Raman signals. The $I_{\mathrm{D}} / I_{\mathrm{G}}$ ratio in Figure $\mathrm{S} 3 \mathrm{a}, \mathrm{b}$ is in the range of $0.07-0.23$ and the $I_{\mathrm{D}} / I_{\mathrm{G}}$ ratio of heated graphene is below 0.23. This result indicates that the thermal treatment of functionalized graphene regenerates the $s p^{2}$-hybridized carbon lattice almost completely. Since other types of defects such as edges, basal plane vacancies or dopant atoms cannot be completely removed at $450{ }^{\circ} \mathrm{C}$, the $\mathrm{D}$ peak observed in graphene after the reductive functionalization in this study should originate from $s p^{3}$-hybridized carbon atoms. ${ }^{3}$ The surface morphology of the heated graphene investigated by SEM (Figure S3c) and AFM (Figure S3d, e) shows the existence of wrinkles, damage and impurities. 

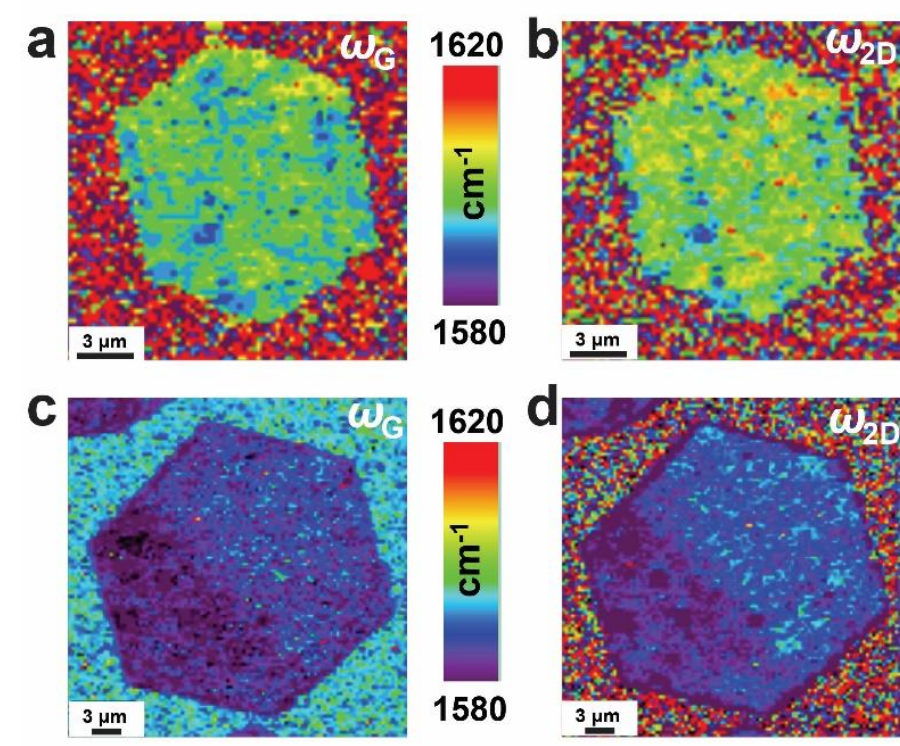

d

e

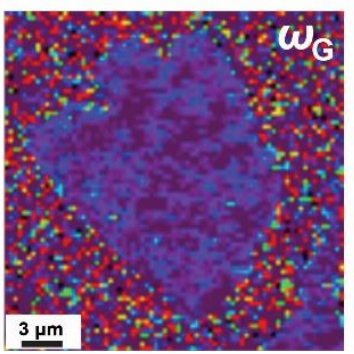

$1620 f$

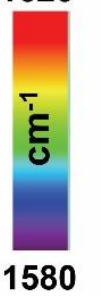

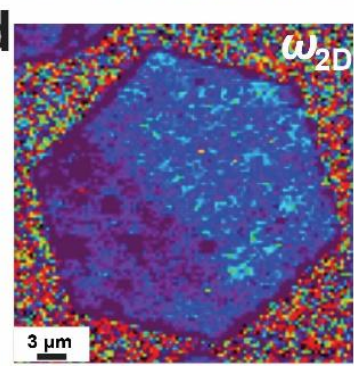

2780

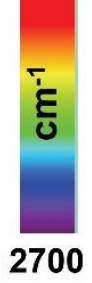

2780

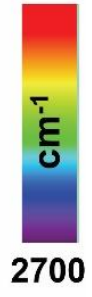

2780

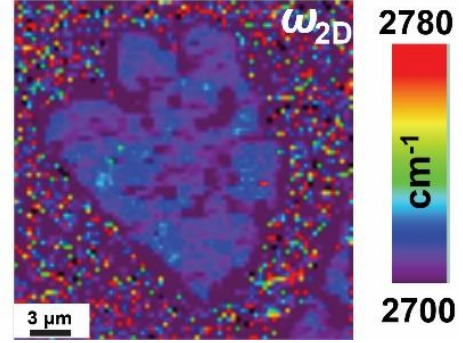

Figure S4. (a, b) Raman frequency ( $\omega$ ) maps of the (a) G and (b) 2D bands of the untreated 1L island on $\mathrm{Cu}(111)$ in Figure 2a. (c, d) (c) $\omega_{\mathrm{G}}$ and (d) $\omega_{2 \mathrm{D}}$ maps of the untreated $1 \mathrm{~L}$ island on $\mathrm{Cu}(100)$ in Figure $2 \mathrm{~b}$. (e, f) (e) $\omega_{\mathrm{G}}$ and (f) $\omega_{2 \mathrm{D}}$ maps of the untreated $1 \mathrm{~L}$ island on $p$-Cu in Figure 2c.

The Raman frequency $(\omega)$ maps in Figure S4 show that the 1L graphene island on $\mathrm{Cu}(111)$ has uniformly blue-shifted $\mathrm{G}$ and $2 \mathrm{D}$ bands over the whole area compared to that on $\mathrm{Cu}(100)$ and $p-\mathrm{Cu}$. This observation suggests to us that $1 \mathrm{~L}$ graphene on $\mathrm{Cu}(111)$ has a significant compressive strain. 

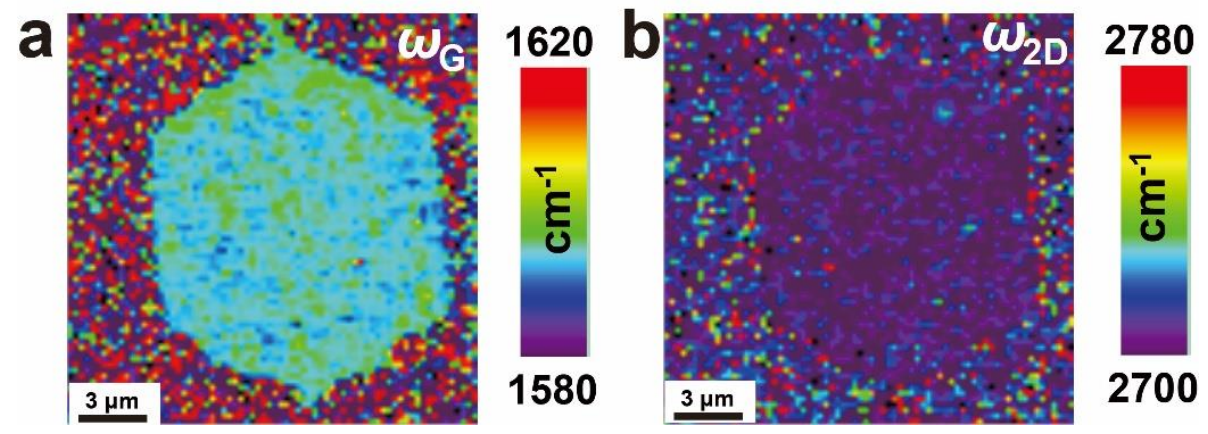

Figure S5. Frequency maps obtained from the $1 \mathrm{~L}$ island on $\mathrm{Cu}(111)$ in Figure $2 \mathrm{a}$ after the $3^{\text {rd }}$ functionalization run. (a) $\omega_{\mathrm{G}}$ map. (b) $\omega_{2 \mathrm{D}}$ map.

Figure S5 shows that $\omega_{\mathrm{G}}$ and $\omega_{2 \mathrm{D}}$ of $1 \mathrm{~L}$ island on $\mathrm{Cu}(111)$ underwent redshifts after reductive functionalization, suggesting to us that the compressive strain in the graphene was partially relaxed. 

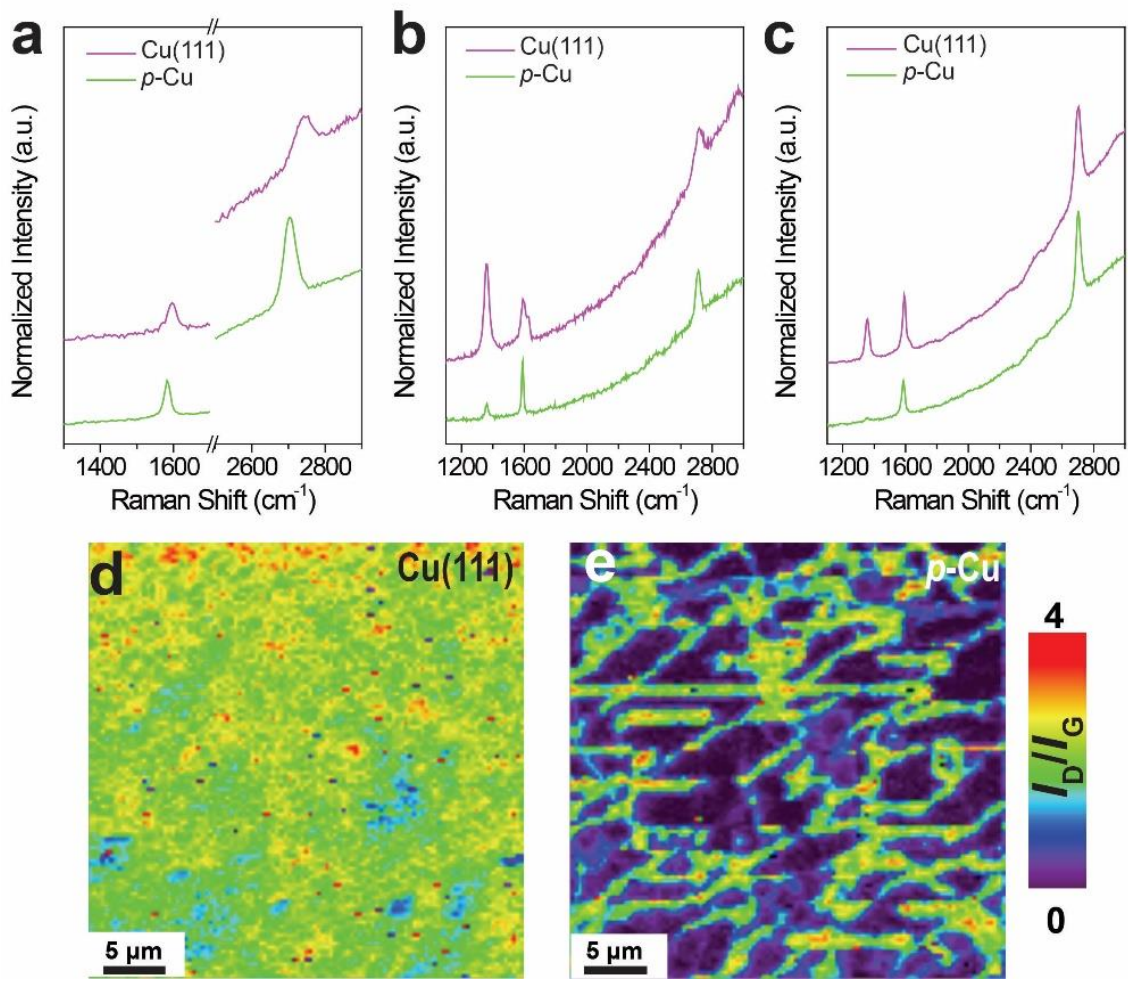

Figure S6. (a) Raman spectra of continuous 1L graphene films on $\mathrm{Cu}(111)$ and $p$-Cu before functionalization. (b) Raman spectra recorded from graphene after attempted functionalization with iodobenzene. Reaction conditions: concentration of $\left.\left[\left[\mathrm{K}(15 \text {-crown-5 })_{2}\right]\right]_{\mathrm{Na}}\right]_{0}\left(\left[C_{\mathrm{NaK}}\right]_{0}\right)=$ $0.02 \mathrm{M} ; t_{1}=5 \mathrm{~min} ; t_{2}=5 \mathrm{~min}$; temperature $(T)=20^{\circ} \mathrm{C}$. (c) Raman spectra recorded from graphene after functionalization with bromobenzene. Reaction conditions: $\left[C_{\mathrm{NaK}}\right]_{0}=0.04 \mathrm{M} ; t_{1}$ $=10 \mathrm{~min} ; t_{2}=5 \mathrm{~min} ; T=20^{\circ} \mathrm{C}$. $(\mathrm{d}-\mathrm{e}) I_{\mathrm{D}} / I_{\mathrm{G}}$ maps of continuous $1 \mathrm{~L}$ graphene films on $(\mathrm{d}) \mathrm{Cu}(111)$ and (e) $p$-Cu after attempted functionalization with iodobenzene. Reaction conditions: $\left[C_{\mathrm{NaK}}\right]_{0}$ $=0.02 \mathrm{M} ; t_{1}=5 \min ; t_{2}=5 \min ; T=20^{\circ} \mathrm{C}$.

The differences in reactivity induced by the $\mathrm{Cu}$ substrate shown in Figures 1 and 2 for graphene islands were also observed for continuous graphene films. Figures S6a-c shows that continuous $1 \mathrm{~L}$ graphene films on $\mathrm{Cu}(111)$ were functionalized to a higher degree than those on $p-\mathrm{Cu}$ when either iodobenzene or bromobenzene was used as the 
reagent. The relatively uniform $I_{\mathrm{D}} / I_{\mathrm{G}}$ map in Figure $S 6 \mathrm{~d}$ suggests that the functionalization of a continuous $1 \mathrm{~L}$ graphene on $\mathrm{Cu}(111)$ was uniform. In contrast, the $I_{\mathrm{D}} / I_{\mathrm{G}}$ map in Figure S6e shows both functionalized and non-functionalized regions, indicating that the $\mathrm{Cu}$ substrate, rather than the size of the graphene, affects the functionalization.

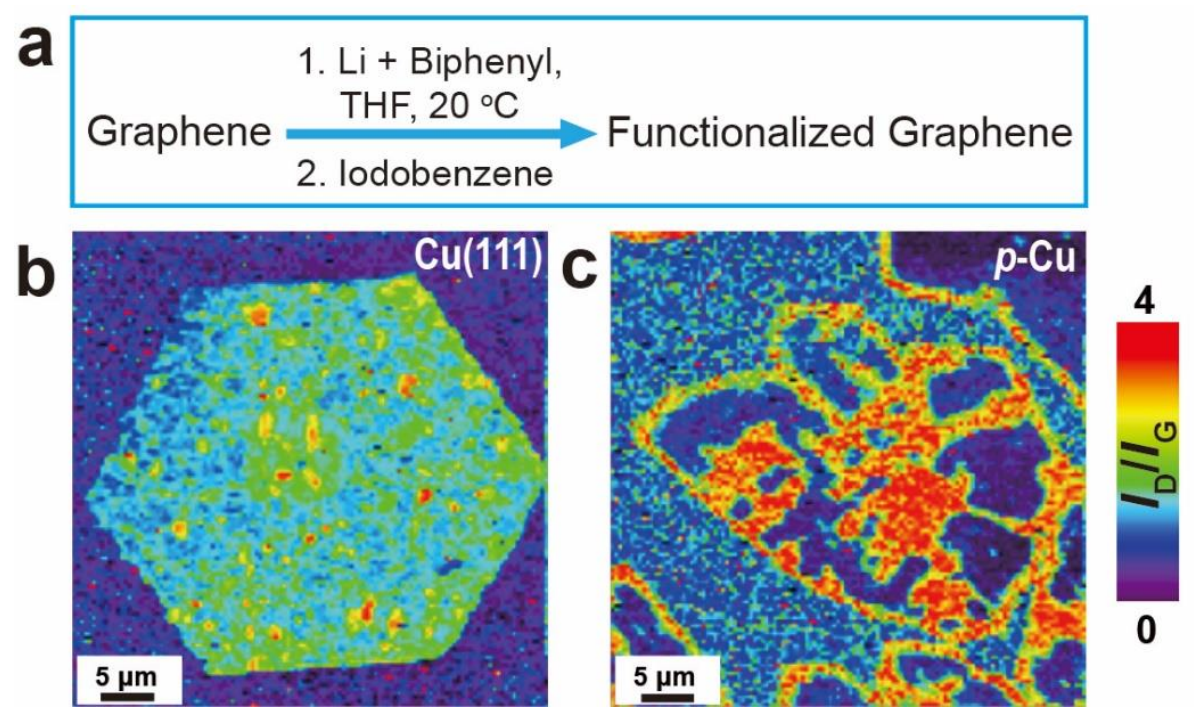

Figure S7. Functionalization of graphene islands on $\mathrm{Cu}$ using lithium in a biphenyl reductive solution. (a) Scheme of the reductive functionalization. (b) $I_{\mathrm{D}} / I_{\mathrm{G}}$ map of a functionalized $1 \mathrm{~L}$ island on $\mathrm{Cu}(111)$. (c) $I_{\mathrm{D}} / I_{\mathrm{G}}$ map of a functionalized $1 \mathrm{~L}$ island on $p-\mathrm{Cu}$. Reaction conditions: $\left[C_{L i}\right]_{0}=0.2 \mathrm{M} ; t_{1}=2 \mathrm{~min} ; t_{2}=5 \mathrm{~min} ; T=20^{\circ} \mathrm{C}$.

We attempted to functionalize $1 \mathrm{~L}$ graphene islands on $\mathrm{Cu}(111)$ and $p$ - $\mathrm{Cu}$ using a reductive solution prepared by dissolving lithium in a THF solution containing biphenyl. The $I_{\mathrm{D}} / I_{\mathrm{G}}$ maps for each sample in Figure $\mathrm{S} 7$ show a reaction behavior similar to when using $[\mathrm{K}(15$-crown-5)2 $] \mathrm{Na}$ (Figure 2). 

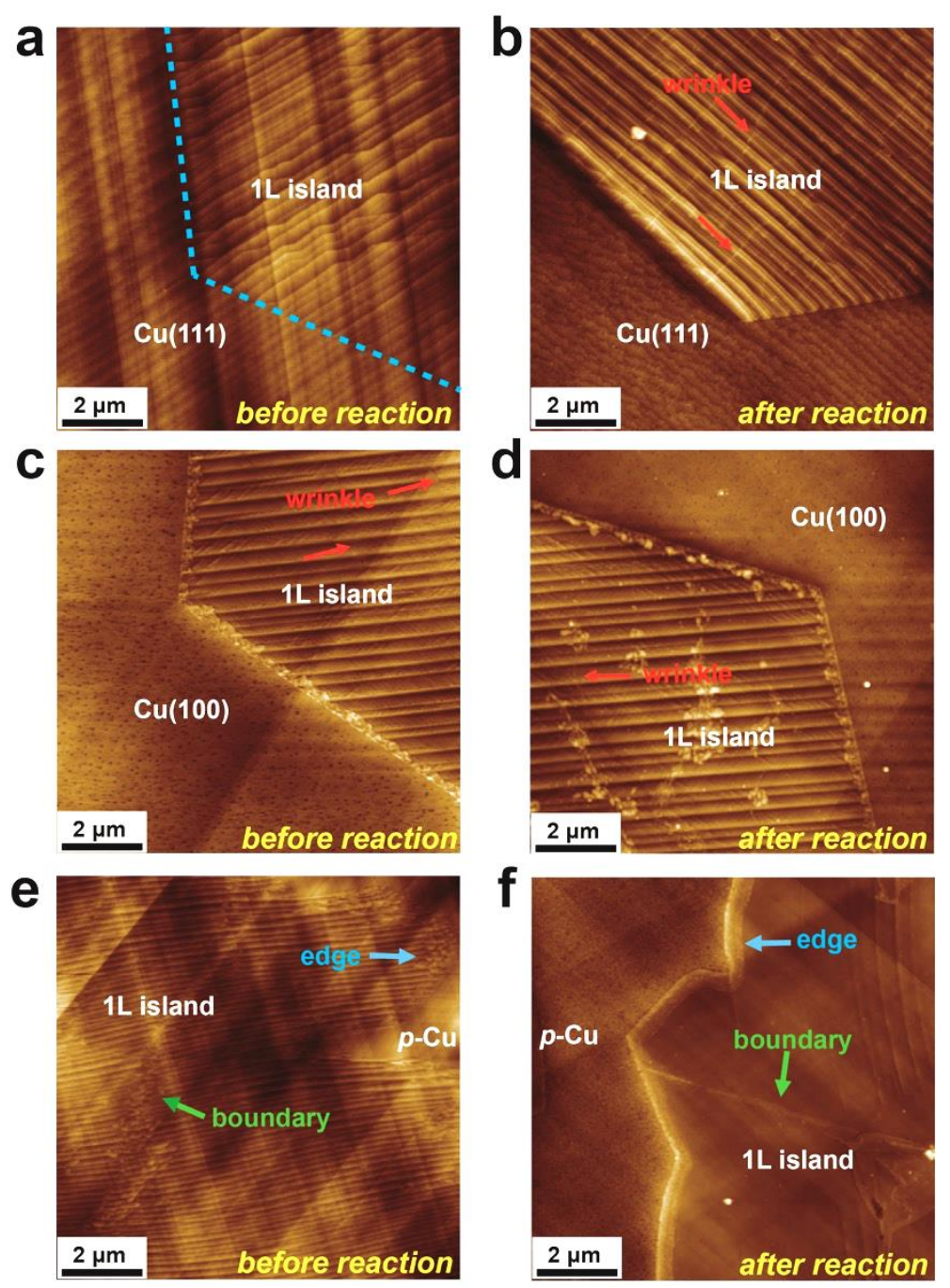

Figure S8. (a, b) AFM height images acquired from (a) an unreacted island and (b) a reacted island on $\mathrm{Cu}(111)$. (c, d) AFM height images of (c) an unreacted island and (d) a reacted island on $\mathrm{Cu}(100)$. (e, f) AFM height images of (e) an unreacted island and (f) a reacted island on $p$ $\mathrm{Cu}$. Reaction conditions: $\left[C_{\mathrm{NaK}}\right]_{0}=0.02 \mathrm{M} ; t_{1}=5 \mathrm{~min} ; t_{2}=5 \mathrm{~min} ; T=20^{\circ} \mathrm{C}$; iodobenzene was used as a coupling reagent (see text).

The morphologies of 1L graphene islands on the three $\mathrm{Cu}$ substrates before and after functionalization (from the same batch of graphene shown in Figure 2 for each substrate) were examined by atomic force microscopy (AFM). Figure S8a shows the AFM image 
of a typical unreacted island on $\mathrm{Cu}(111)$ with a measured surface roughness $\left(R_{a}\right)$ of 4.1 $\mathrm{nm}$ in this area. Corrugated $\mathrm{Cu}$ steps are clearly seen in the region covered by the graphene; these steps are created by the bunching of smaller surface steps due to the presence of graphene. Our recent work explained that step bunching is enabled by the fast diffusion of metal adatoms underneath the graphene layer and is driven by the release of local bending energy of the graphene overlayer in the vicinity of surface steps on the metal surface. ${ }^{1}$ Such islands have few to no wrinkles in contrast to islands grown on a $p-\mathrm{Cu}$ surface under the conditions of our AFM measurement. The presence of $\mathrm{Cu}$ steps and the absence of wrinkles as well as further details on the compressive strain in such samples were discussed in a previous paper. ${ }^{4}$ The reductive functionalization led to a more distinct contrast between the graphene-covered region and the bare $\mathrm{Cu}$ in Figure S8b, which is most likely due to the presence of phenyl groups as well as, perhaps, some physically adsorbed molecules. The functionalization of this island on $\mathrm{Cu}(111)$ is relatively uniform and typical for many islands. Since many graphene wrinkles are observed in the functionalized sample, we surmise that the wrinkles are created due to the relaxation of compressive strain from functionalization. Figure S8c shows an AFM image of a typical unreacted island on $\mathrm{Cu}(100)$ with a measured $R_{a}$ in this area of $3.8 \mathrm{~nm}$. The fact that the bare $\mathrm{Cu}(100)$ surface lost its crystal terraces may be due to minor oxidation when exposed to air, which makes the edges of the graphene islands clear. Wrinkles can often be observed in such samples, as also seen in the SEM image in Figure S1d. After functionalization, while most regions of the graphene island remained unchanged, some areas became rougher, possibly due to non-uniform 
functionalization. Such non-uniformity in functionalization was also observed for a graphene island on $p$-Cu. Figure S8e shows a representative image of an island on $p$ $\mathrm{Cu}\left(R_{a}=8.0 \mathrm{~nm}\right)$. Some lines that are similar to graphene edges are found in the interior region, and these are likely either graphene boundaries formed during the growth or newly-formed edges due to 'cracking' (fracture) of the film. Although the Raman $I_{\mathrm{D}} / I_{\mathrm{G}}$ map cannot detect such lines in unreacted graphene, a high reactivity at these locations is still expected. After functionalization, the Raman maps of the edge and boundary regions of the island differ from that of the interior region (Figure S8f), indicating a non-uniform reaction. Since the roughness of these graphene islands is of the same scale, the influence of surface roughness (on this scale) in reductive functionalization is evidently less important, or even negligible, compared to other factors. 


\section{Computational details}

\section{Molecular dynamics (MD) simulations}

All-atom molecular dynamics (MD) simulations were performed with the COMPASS II force field in the Forcite program ${ }^{5}$ to describe the interaction between a graphene flake and the $\mathrm{Cu}$ substrate (111) surface. The atom-based summation method was used for the short-range van der Waals interactions with a cut-off distance of $15 \AA$. Longrange electrostatic interactions were computed using the Ewald summation method with an accuracy of $1 \times 10^{-4} \mathrm{kcal} / \mathrm{mol}^{6,7}$ The $N V T$ (i.e., canonical ensemble) MD simulation was performed with the Berendsen thermostat at room temperature for $1 \mathrm{~ns}$ with a time step of $1 \mathrm{fs}^{8}$

As shown in Figure S9, regular hexagonal graphene with a hydrogenated zigzag edge composed of 1,944 carbons, 108 hydrogens, and a 9-layer periodic $\mathrm{Cu}(111)$ substrate of 15,444 copper atoms $(9.73 \mathrm{~nm} \times 9.96 \mathrm{~nm})$ were used. The height of the simulation box was extended to $50 \mathrm{~nm}$ along the $z$-direction to avoid self-interaction. Note that the

two lowest $\mathrm{Cu}$ layers were fixed to represent the bulk phase. A Hirshfeld charge, ${ }^{9}$ obtained from DFT calculation (Figure S10), was applied to the geometrically optimized system.

Density functional theory (DFT) calculations

Density functional theory (DFT) calculations using the $\mathrm{DMol}^{3}$ program were used to elucidate the effect of compressive strain on graphene covalent functionalization. ${ }^{10,11}$ 
The generalized gradient approximation (GGA) with Perdew-Burke-Ernzerhof (PBE) functional ${ }^{12}$ was used while a long range dispersion correction accounting for the van der Waals interaction was implemented by Grimme's D2 method. ${ }^{13}$ The spin-polarized calculation was used with double numerical plus polarization (DNP) of the 4.4 level as the basis set. Core treatment was conducted with density functional semicore pseudopotentials ${ }^{14}$ with a global orbital cutoff radius of $5.6 \AA$ and a smearing value of $0.005 \mathrm{Ha}$. The Brillouin-zone was sampled by a $1 \times 1 \times 1 k$-point using the MonkhorstPack scheme. ${ }^{15}$ A transition state (TS) search calculation was performed to investigate the kinetic barrier to the covalent functionalization of graphene, where the linear and quadratic synchronous transit (LST/QST) method was used with the conjugated gradient (CG) refinement ${ }^{16}$ with $0.01 \mathrm{Ha} / \AA$ for RMS convergence. An implicit THF environment was achieved by using a conductor-like screening model (COSMO) scheme ${ }^{17}$ with a dielectric constant of 7.47 (THF at $20^{\circ} \mathrm{C}^{18}$ ).

For the reactants of the covalent functionalization of graphene, single layer graphene consisting of 98 carbon atoms, was located in the simulation box (i.e., $17.3 \times 17.3 \times$ $40.0 \AA^{3}$ for unstrained $7 \times 7$ graphene supercells), where a vacuum region perpendicular to the graphene (along the $z$-direction) was introduced (i.e., $30 \AA$ ) to minimize selfinteraction (Figure S11a). 15-crown-5, Na, K, and iodobenzene were introduced as the reactants to facilitate the covalent functionalization of graphene (Figure S11b). To investigate the effect of compressive strain on the reaction, we applied $-0.1,-0.2,-0.3$, -0.4 , and $-0.5 \%$ biaxial strains to the graphene. The phenyl group in iodobenzene was chemically adsorbed on the graphene after breaking the bond between the halogen atom 
and the phenyl group. The 15-crown-5, Na, K, and I species as well as the functionalized graphene were fully optimized after the adsorption of the phenyl group on the graphene.

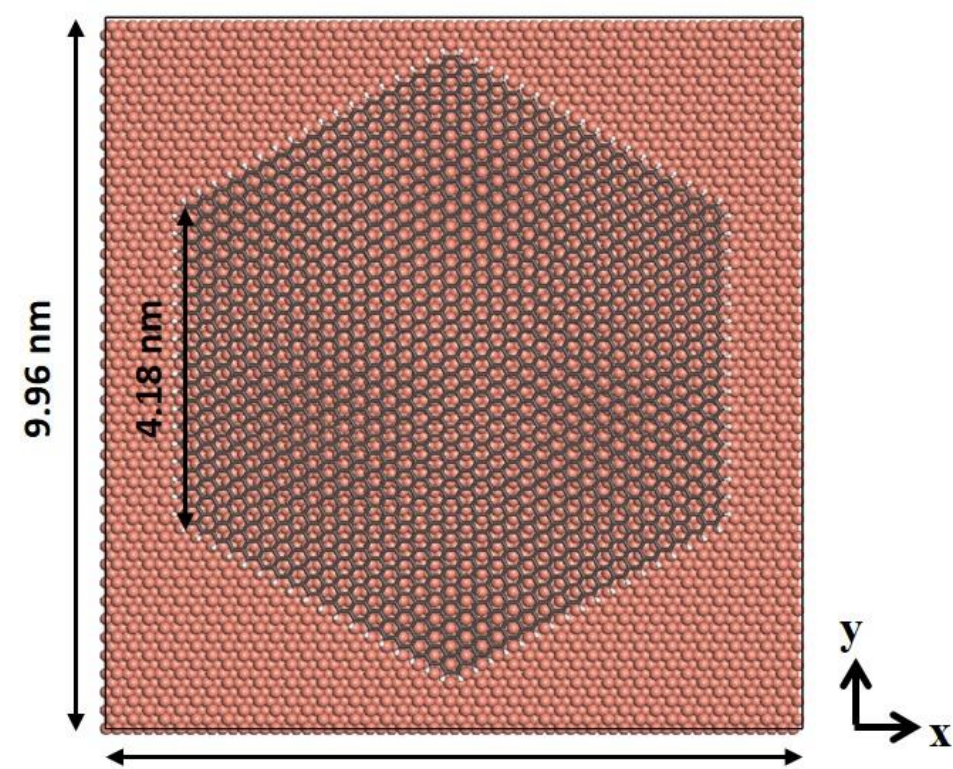

$9.73 \mathrm{~nm}$

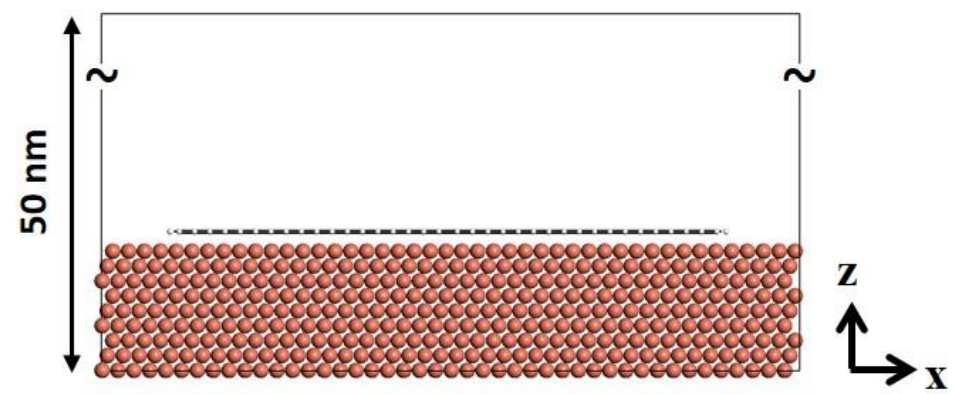

Figure S9. Structure of the graphene flake on $\mathrm{Cu}(111)$ used in the MD simulation. The white and orange spheres represent the $\mathrm{H}$ and $\mathrm{Cu}$ atoms, respectively. The dark-gray honeycomb network represents a layer of graphene. 

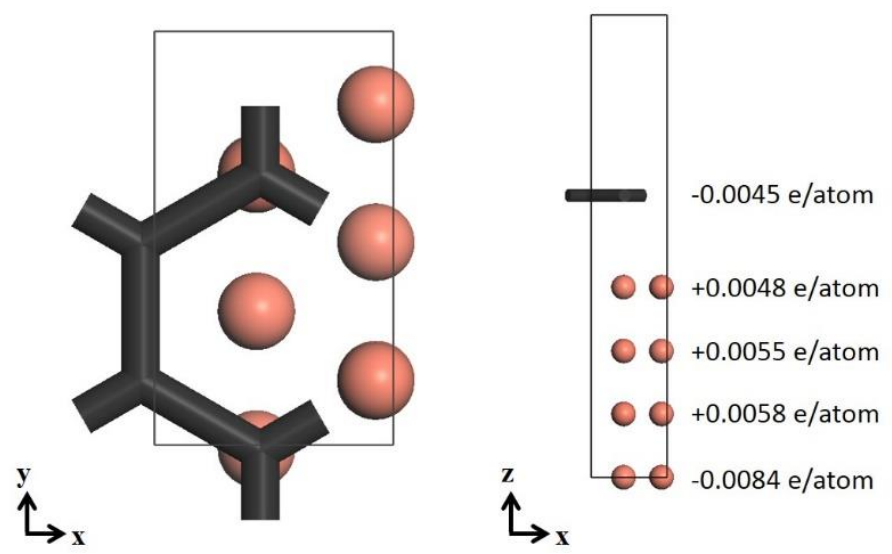

Figure S10. The optimized structure of a periodic graphene/Cu system consisting of single layer graphene and 4-layer $\mathrm{Cu}$ substrate. The numbers in the right panel are the averaged Hirshfeld charge for each layer. Orange spheres are $\mathrm{Cu}$ atoms. The dark-gray honeycomb network is a part of the graphene layer. The bottom $\mathrm{Cu}$ layer was fixed to represent the bulk phase.

a
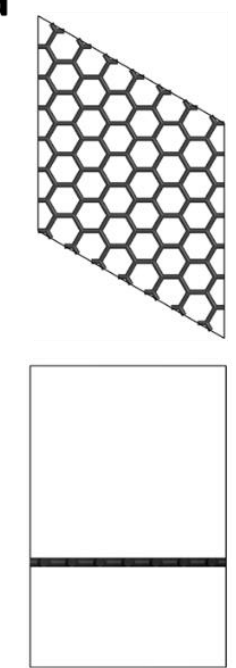

Graphene b
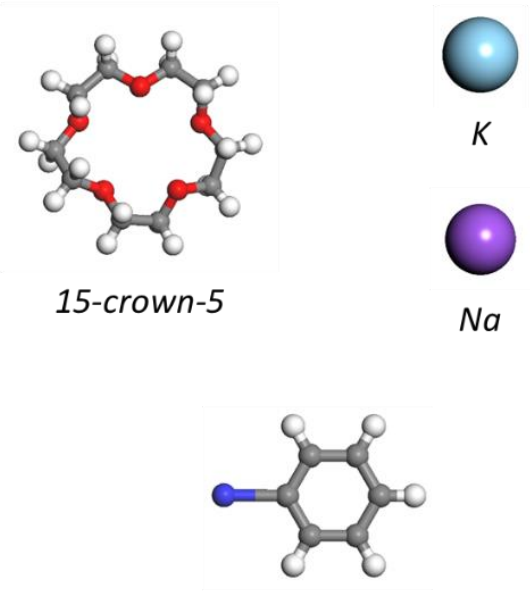

iodobenzene

Figure S11. The structures of (a) graphene, (b) 15-crown-5, K, Na, and iodobenzene used in the

DFT calculations. White, red, light blue, purple, blue, and gray spheres represent $\mathrm{H}, \mathrm{O}, \mathrm{K}, \mathrm{Na}$,

I, and C atoms respectively. The dark gray honeycomb network represents a layer of graphene. 


\section{$0.00 \%$}

a

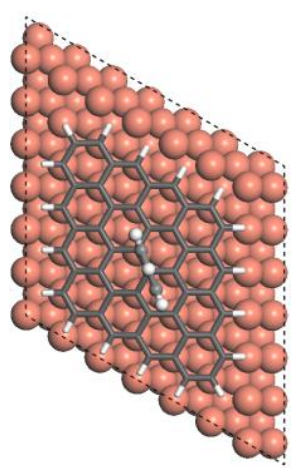

b

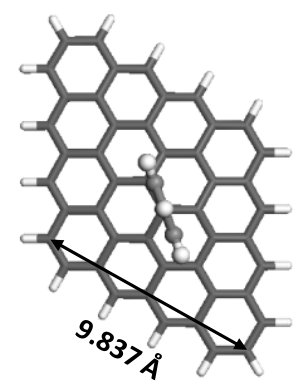

$-0.30 \%$
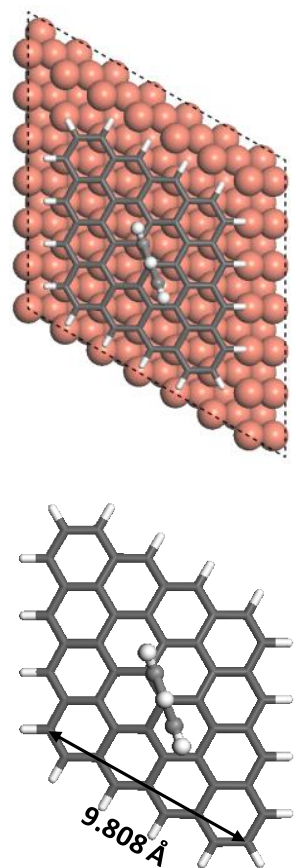

$-0.50 \%$
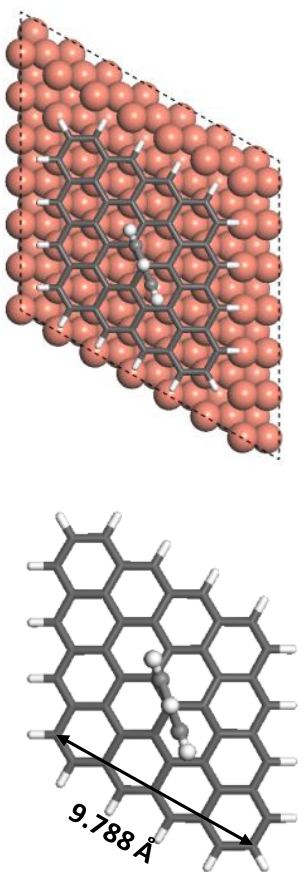

Figure S12. Top view of the lowest energy structures of (a) a graphene flake, which was functionalized with a phenyl group, on top of a $\mathrm{Cu}$ (111) substrate and (b) a graphene flake functionalized with a phenyl group under different degrees of compressive strain (indicated). The outermost carbon atoms of the graphene flakes were constrained during the geometry optimization process to describe a pristine or compressed graphene lattice. Orange, gray, and white balls represent $\mathrm{Cu}, \mathrm{C}$, and $\mathrm{H}$ atoms, respectively. The COSMO method was used to account for solvent effects and to calculate the dielectric constant of THF.

The binding energies between the functionalization reagent and a graphene flake under increasing compressive strain and in the presence of the $\mathrm{Cu}$ substrate were also calculated (Figure S12). The data indicated that the $\mathrm{Cu}$ substrate increased the binding strength by approximately $0.34 \sim 0.37 \mathrm{eV}$ (Table S2). 
Table S2. Binding energy $\left(\boldsymbol{E}_{\text {binding }}\right)$ of a phenyl group on a graphene flake with or without a $\mathrm{Cu}$ substrate at $0.00,-0.30$, and $-0.50 \%$ strain. Note that the binding energy was estimated by the energy released after the adsorption of the phenyl group on the graphene $\left(\boldsymbol{E}_{\text {binding }}=\right.$ $\boldsymbol{E}_{\text {total }}-\left(\boldsymbol{E}_{\boldsymbol{G}}\right.$ or $\left.\boldsymbol{E}_{\boldsymbol{G} / \boldsymbol{C u}}+\boldsymbol{E}_{\text {phenyl group }}\right)$. The total energy of the phenyl -adsorbed system on the graphene flake is expressed as $\boldsymbol{E}_{\text {total }}$ while the total energies of the graphene flake, the graphene flake with a $\mathrm{Cu}$ substrate, and the phenyl group are expressed as $\boldsymbol{E}_{\boldsymbol{G}}, \boldsymbol{E}_{\boldsymbol{G} / \boldsymbol{C u}}$ and $\boldsymbol{E}_{\text {phenyl group }}$, respectively.

\begin{tabular}{ccc}
\hline Strain & Graphene flake/Cu & Graphene flake \\
\hline $0.00 \%$ & $-1.4825 \mathrm{eV}$ & $-1.1414 \mathrm{eV}$ \\
$-0.30 \%$ & $-1.5055 \mathrm{eV}$ & $-1.1483 \mathrm{eV}$ \\
$-0.50 \%$ & $-1.5195 \mathrm{eV}$ & $-1.1546 \mathrm{eV}$ \\
\hline
\end{tabular}

To investigate the energetic relation between graphene deformation and the interactions formed between graphene and $\mathrm{Cu}(111)$, DFT calculations were performed using graphene flake models (Figure S12). The results are shown in Table S3. It was found that the deformation energy of graphene decreased as applied compressive strain increased. Also, the binding energy between graphene and the $\mathrm{Cu}$ substrate decreased as the compressive strain increased. Thus, the deformation energy of the graphene becomes lower with increasing compressive strain while interaction between graphene and $\mathrm{Cu}$ substrate is weakened. 
Table S3. Deformation energy ( $E_{\text {deform }}$ ) of graphene on a $\mathrm{Cu}$ substrate and the binding energy $\left(E_{G / C u \_b i n d i n g}\right)$ between graphene and the $\mathrm{Cu}$ substrate at $0.00,-0.30$, and $-0.50 \%$ strain. Note that the deformation energy was estimated by the energy required by the graphene for the structural change of the functionalization reaction $\left(E_{\text {deform }}=E_{G_{-} \text {deform }}-E_{G_{-} \text {relaxed }}\right)$. The total energy of the graphene flake in the deformed state on $\mathrm{Cu}$ is expressed as $E_{G_{-} \text {deform }}$ and the total energy of the relaxed graphene flake on $\mathrm{Cu}$ is expressed as $E_{G_{-} \text {relaxed }}$. The binding energy between graphene and $\mathrm{Cu}$ substrate was calculated by $E_{G / C u_{-} \text {binding }}=E_{G / C u}-\left(E_{G}+\right.$ $E_{C u}$ ), where the total energies of the graphene flake with a $\mathrm{Cu}$ substrate, an isolated graphene flake and the underlying $\mathrm{Cu}$ substrate are expressed by $E_{G / C u}, E_{G}$ and $E_{C u}$, respectively.

\begin{tabular}{lll}
\hline Strain & $E_{\text {deform }}$ & $E_{\text {G/Cu_binding }}$ \\
\hline $0.00 \%$ & $1.3103 \mathrm{eV}$ & $-0.1589 \mathrm{eV} /$ atom \\
$-0.30 \%$ & $1.3078 \mathrm{eV}$ & $-0.1566 \mathrm{eV} /$ atom \\
$-0.50 \%$ & $1.3037 \mathrm{eV}$ & $-0.1551 \mathrm{eV} /$ atom \\
\hline
\end{tabular}




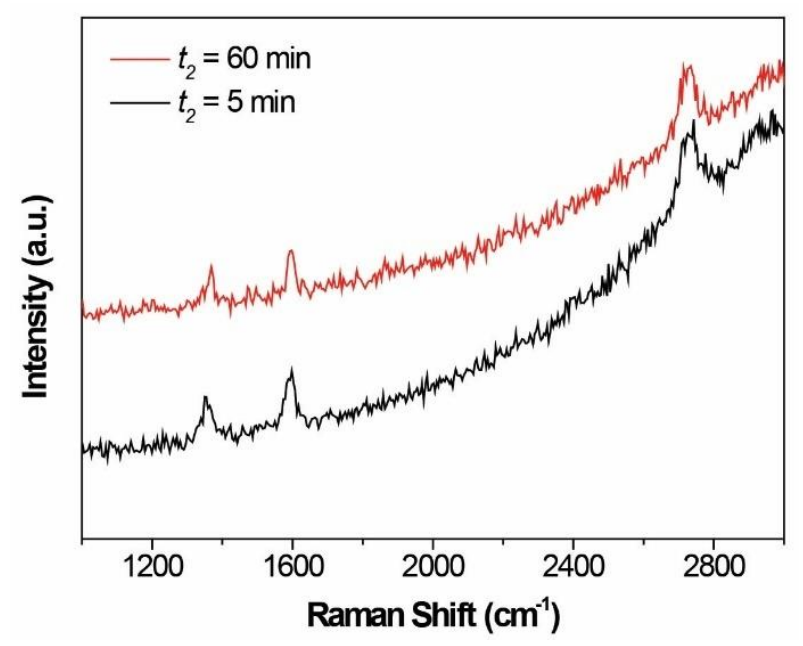

Figure $\mathrm{S} 13$. Raman spectra of $1 \mathrm{~L}$ islands on $\mathrm{Cu}(111)$ functionalized for different periods of time $\left(t_{2}\right)$.

Figure $\mathrm{S} 13$ shows the spectra of $1 \mathrm{~L}$ islands on $\mathrm{Cu}(111)$ reacted for different times in the second step $\left(t_{2}\right)$. It is seen that $t_{2}$ does not influence the functionalization degree; this result is accordance with previous conclusions on the functionalization of graphene on $\mathrm{SiO}_{2} / \mathrm{Si}^{3}$
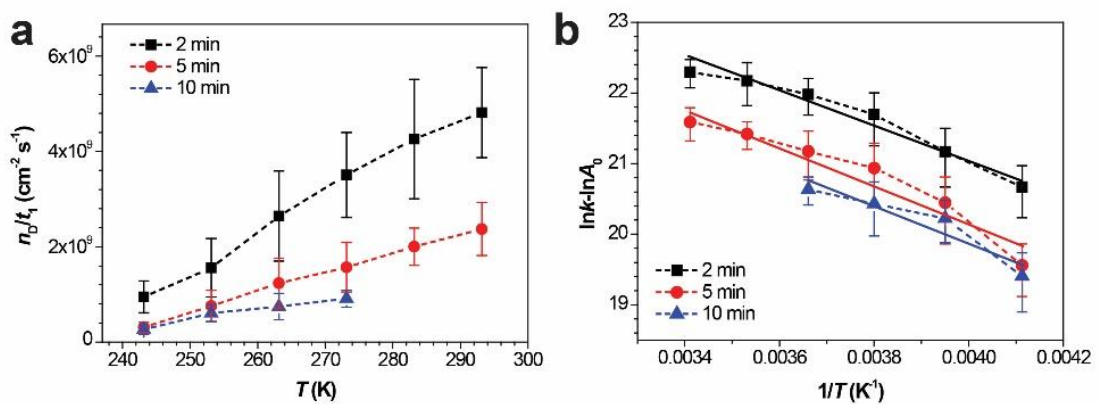

Figure S14. (a) The average reaction rate (represented by defect density $\left.\left(n_{\mathrm{D}}\right) / t_{1}\right)$ as a function of $T$.

(b) Relationship between $\ln k$ and 1/T. Error bars represent the standard deviations.

It is known that the change in the graphene Raman spectrum with increasing defect density $\left(n_{\mathrm{D}}\right)$ shows two typical stages. ${ }^{19-22}$ In stage I, where $n_{\mathrm{D}}$ is relatively low, $I_{\mathrm{D}} / I_{\mathrm{G}}$ 
increases with increasing $n_{\mathrm{D}}$ due an increase in the defect-activated $\mathrm{D}$ peak. At this stage, the $\mathrm{D}$ and $2 \mathrm{D}$ peaks are relatively sharp and the defect density $n_{\mathrm{D}}$ can be calculated from equation $(1)^{21}$

$n_{\mathrm{D}}\left(\mathrm{cm}^{-2}\right)=(7.3 \pm 2.2) \times 10^{9} E_{\mathrm{L}}^{4}\left(\frac{I_{\mathrm{D}}}{I_{\mathrm{G}}}\right)$

where $E_{\mathrm{L}}$ is the laser energy (in electron volts). In stage II when $n_{\mathrm{D}}$ is relatively high due to the overlap of different defect-activated regions, ${ }^{22}$ the $\mathrm{D}$ peak becomes broad and less intense. As a result, $I_{\mathrm{D}} / I_{\mathrm{G}}$ decreases with increasing $n_{\mathrm{D}}$. In addition, the $2 \mathrm{D}$ peak is very weak and broad in stage II, in contrast to the narrow peak in stage I, which means that in stage II, $n_{\mathrm{D}}$ cannot be calculated from $I_{\mathrm{D}} / I_{\mathrm{G}} \cdot{ }^{19-22}$ By comparing the data in Figures $5 \mathrm{c}$, d with the changes in the Raman spectra $\left(n_{\mathrm{D}}\right)$, the spectra of $1 \mathrm{~L}$ islands functionalized at $T=10{ }^{\circ} \mathrm{C} ; t_{1}=10$ or $20 \mathrm{~min}$ (Figure $5 \mathrm{c}$ ) and at $T=10$ or $20^{\circ} \mathrm{C} ; t_{1}=$ 10 min (Figure $5 \mathrm{~d}$ ), can be assigned to stage II. The lower $I_{\mathrm{D}} / I_{\mathrm{G}}$ values with increased $t_{1}$ (Figure $\left.5 \mathrm{c}\right)$ or $T$ (Figure $5 \mathrm{~d}$ ) are due to an increase in $n_{\mathrm{D}}$

The reductive functionalization of graphene is a process that occurs at the graphenesolution interface. To better understand the kinetics deduced from experimental data, several assumptions were made.

(1) Since $\left[\mathrm{K}(15 \text {-crown-5 })_{2}\right] \mathrm{Na}$ and iodobenzene are in excess, we assume that the concentrations of $\left[\mathrm{K}(15 \text {-crown-5 })_{2}\right] \mathrm{Na}$ and iodobenzene do not influence the degree of functionalization on $\mathrm{Cu}(111)$. A similar result was obtained for continuous graphene films on $\mathrm{Cu}(111)$. 
(2) In principle, with more phenyl groups being attached to graphene, the reaction rate $(r)$ is lowered due to a decrease in the density of $s p^{2}-\mathrm{C}$ atoms $\left(n_{\mathrm{C}}\right)$ in graphene as well as due to steric hindrance from the attached groups. As a result, the functionalization may saturate when $t_{1}$ is long enough. However, for low degrees of functionalization, designated by 'Raman stage I', one can assume that both the decrease in $n_{\mathrm{C}}$ and the steric hindrance are low. Indeed, the maximum functionalization degree in stage I given by equation (1) is only $\sim 0.2 \%$.

(3) All defects are $s p^{3}-\mathrm{C}$ type, which means that equation (1) can be used to quantify the number of $s p^{3}-\mathrm{C}$ atoms in the functionalized graphene.

With the above assumptions, the reaction rate $r$ can be calculated using equation (2):

$r=\frac{\mathrm{d} n_{\mathrm{D}}}{\mathrm{d} t_{1}}=k(T) n_{\mathrm{C}}{ }^{m}$

where $k$ is the reaction rate constant, $n_{\mathrm{C}}$ is the density of non-functionalized carbon atoms, which is a constant according to assumption (2), and $m$ is the reaction order. If we simplify the average reaction rate $r_{\mathrm{a}}$ to be $r$, according to equation (1), the relationship between $r$ and $T$ can be plotted as shown in Figure S14a. Note that the two $I_{\mathrm{D}} / I_{\mathrm{G}}$ values of graphene functionalized at $T=10$ or $20^{\circ} \mathrm{C}\left(t_{1}=10 \mathrm{~min}\right)$ were not used in the calculation because the corresponding Raman spectra are in stage II.

The Arrhenius equation (3) can be considered for the reductive functionalization:

$k(T)=A e^{-\frac{E_{\mathrm{a}}}{R T}}$ 
where $A$ is the pre-exponential factor, $E_{\mathrm{a}}$ the activation energy, and $R$ the universal gas constant.

By combining equations (2) and (3), one obtains equation (4):

$\ln k=\ln A-\frac{E_{a}}{R T}=\ln \left(\frac{n_{D}}{t_{1}}\right)-m \ln n_{\mathrm{C}}$

Replacing $n_{\mathrm{C}}^{-\mathrm{m}}$ by $A_{0}$, which is a constant from the aforementioned assumptions, equation (4) can be stated as:

$\ln \left(\frac{n_{\mathrm{D}}}{t_{1}}\right)=\ln k-\ln A_{0}=-\frac{E_{a}}{R T}+\ln A$

From the relationship between $n_{\mathrm{D}} / t_{1}$ and $T$ shown in Figure $\mathrm{S} 14 \mathrm{a}, \ln k-\ln A_{0}$ was obtained as a function of $1 / T$ as shown in Figure S14b. The three curves obtained at $t_{1}=2,5$ and

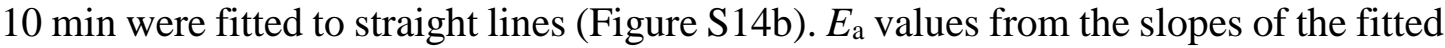
lines are $19.6 \pm 2.0,22.9 \pm 3.2$, and $21.7 \pm 5.4 \mathrm{~kJ} \cdot \mathrm{mol}^{-1}$ for $t_{1}=2,5$ and $10 \mathrm{~min}$, respectively. Therefore, the activation energy for the reductive phenylation of $1 \mathrm{~L}$ islands is estimated to be around $20 \mathrm{~kJ} \cdot \mathrm{mol}^{-1}$. 

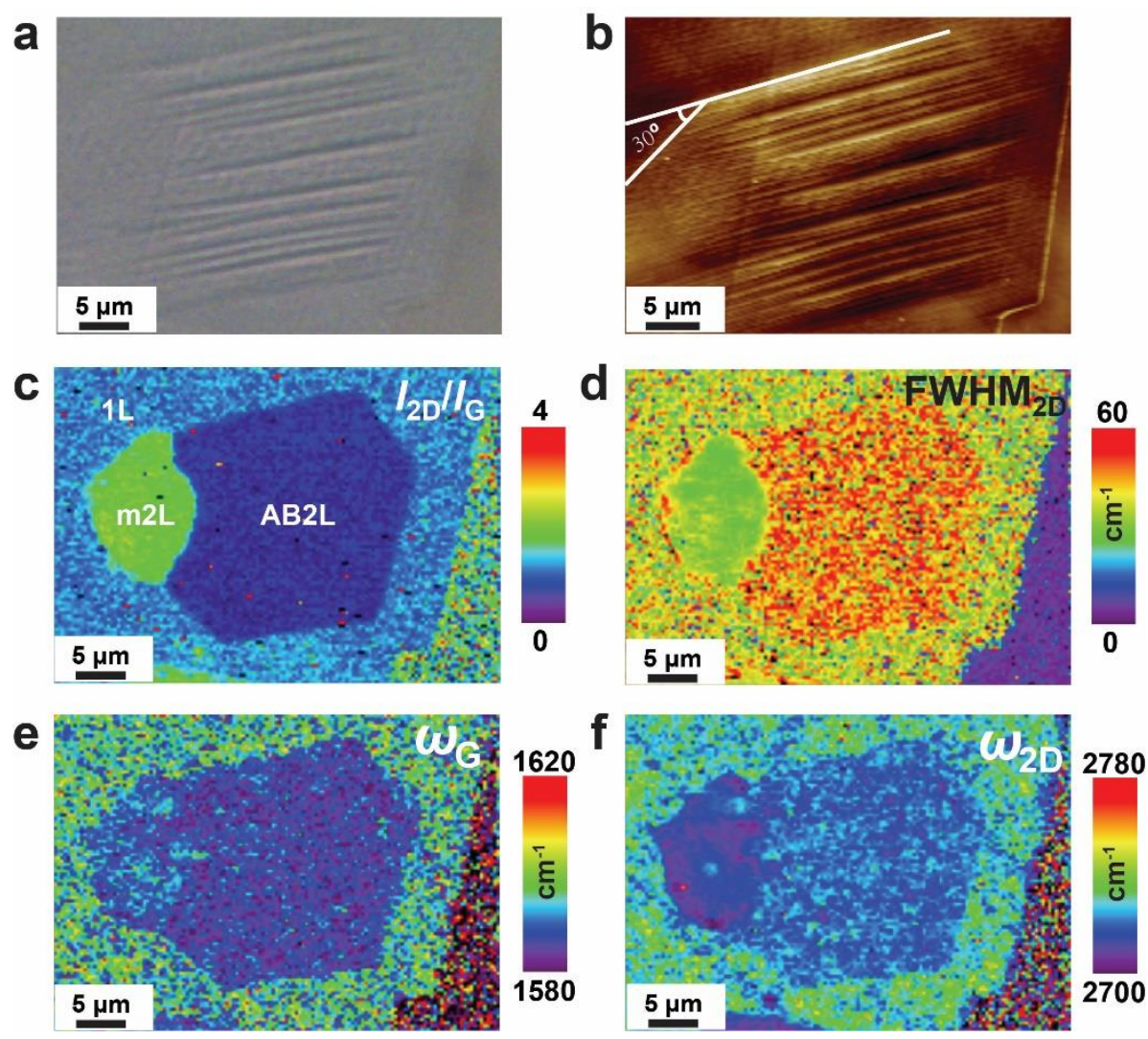

Figure $\mathrm{S} 15$ The graphene island on $\mathrm{Cu}(111)$ shown in Figure 6a before functionalization. (a)

Optical image, (b) AFM height image and (c) Raman $I_{2 \mathrm{D}} / I_{\mathrm{G}}$, (d) FWHM $2 \mathrm{D}$, (e) $\omega_{\mathrm{D}}$ and (f) $\omega_{2 \mathrm{D}}$ maps.

Optical and AFM images of the graphene island on $\mathrm{Cu}(111)$ shown in Figure 6 are shown in Figures S15a, b, where four regions including bare $\mathrm{Cu}(111)$ (bottom right), $1 \mathrm{~L}, \mathrm{AB}$-stacked bilayer $(\mathrm{AB} 2 \mathrm{~L})$ and mis-oriented bilayer $(\mathrm{m} 2 \mathrm{~L})$ regions can be distinguished. Three types of graphene have been assigned based on Raman spectroscopy data as shown in Figure 6a and Figures S15c, d. ${ }^{23,24}$ For example, from their characteristic correlations between $\mathrm{G}$ and $2 \mathrm{D}$ band intensities, $1 \mathrm{~L}, \mathrm{AB} 2 \mathrm{~L}$ and $\mathrm{m} 2 \mathrm{~L}$ regions respectively are shown in blue $\left(I_{2 \mathrm{D}} / I_{\mathrm{G}}=1.3\right)$, purple $\left(I_{2 \mathrm{D}} / I_{\mathrm{G}}=0.6\right)$ and green $\left(I_{2 \mathrm{D}} / I_{\mathrm{G}}=2.0\right)$ in the $I_{2 \mathrm{D}} / I_{\mathrm{G}}$ (height) map (Figure S15c). The two layers in the $\mathrm{m} 2 \mathrm{~L}$ region 
have a rotation angle of $\sim 30^{\circ}$ to each other (Figure S15b). Indeed, a rotation angle of $\sim 0^{\circ}$ or $30^{\circ}$ was observed frequently for our BLG islands on $\mathrm{Cu}(111)$, while other angles were rarely observed. From the optical and AFM images in Figure S15a, b, it is noted that the $\mathrm{AB} 2 \mathrm{~L}$ region shows higher steps than the $\mathrm{m} 2 \mathrm{~L}$ region, which helps in the relaxation of compressive strain. The lower $\mathrm{G}$ and $2 \mathrm{D}$ frequencies of $2 \mathrm{~L}$ than $1 \mathrm{~L}$ shown in Figures $\mathrm{S} 15 \mathrm{e}, \mathrm{f}$ suggest that the compressive strain in $2 \mathrm{~L}$ is weaker than in $1 \mathrm{~L}$ graphene. In addition, when compared to AB2L, m2L has a slightly blue-shifted $\mathrm{G}$ band, as well as a red-shifted 2D band.
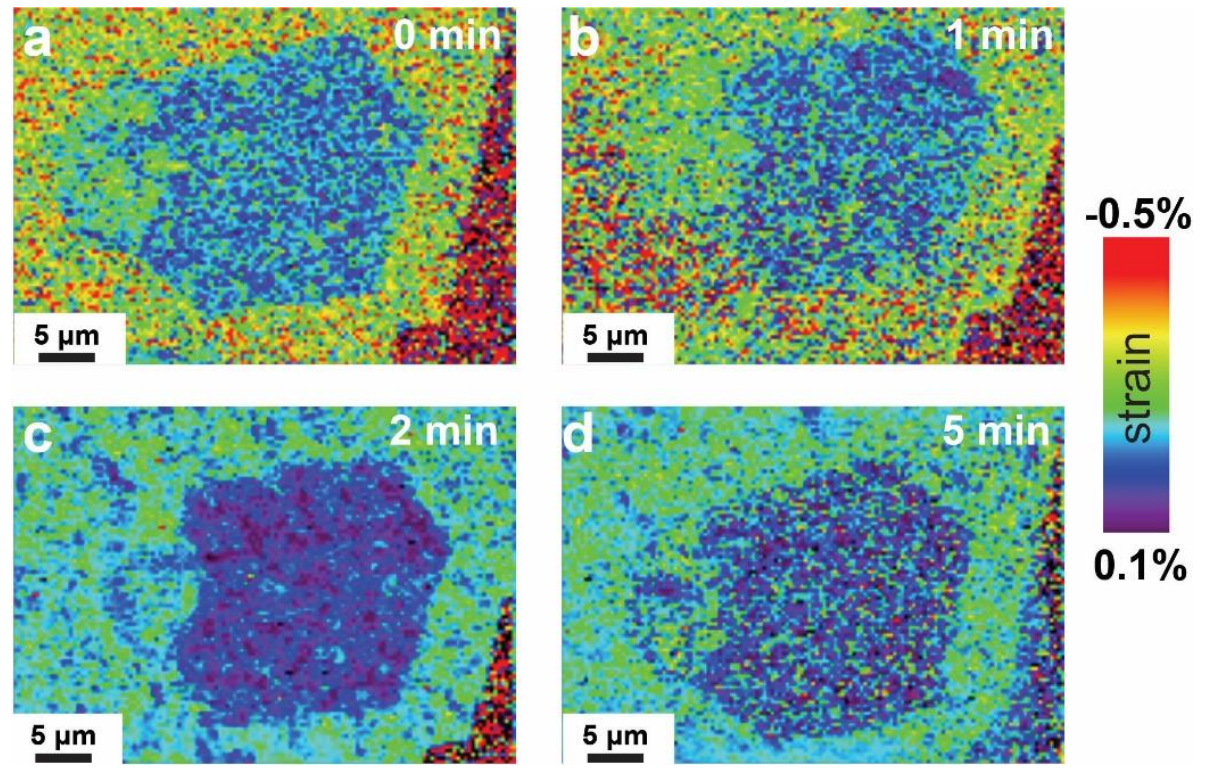

Figure S16. The evolution of strain of a graphene island on $\mathrm{Cu}(111)$ with reaction time $t_{1}$.

In the case of $2 \mathrm{~L}$ graphene, we used the $\mathrm{G}$ band to estimate the compressive strain. The calculated strain map of the graphene island in Figure S15 at each stage of functionalization is shown in Figure S16. Before reaction, the sequence of compression is $1 \mathrm{~L}>\mathrm{m} 2 \mathrm{~L}>\mathrm{AB} 2 \mathrm{~L}$ in this graphene island. All three types of graphene underwent partial compression release during the reaction. 

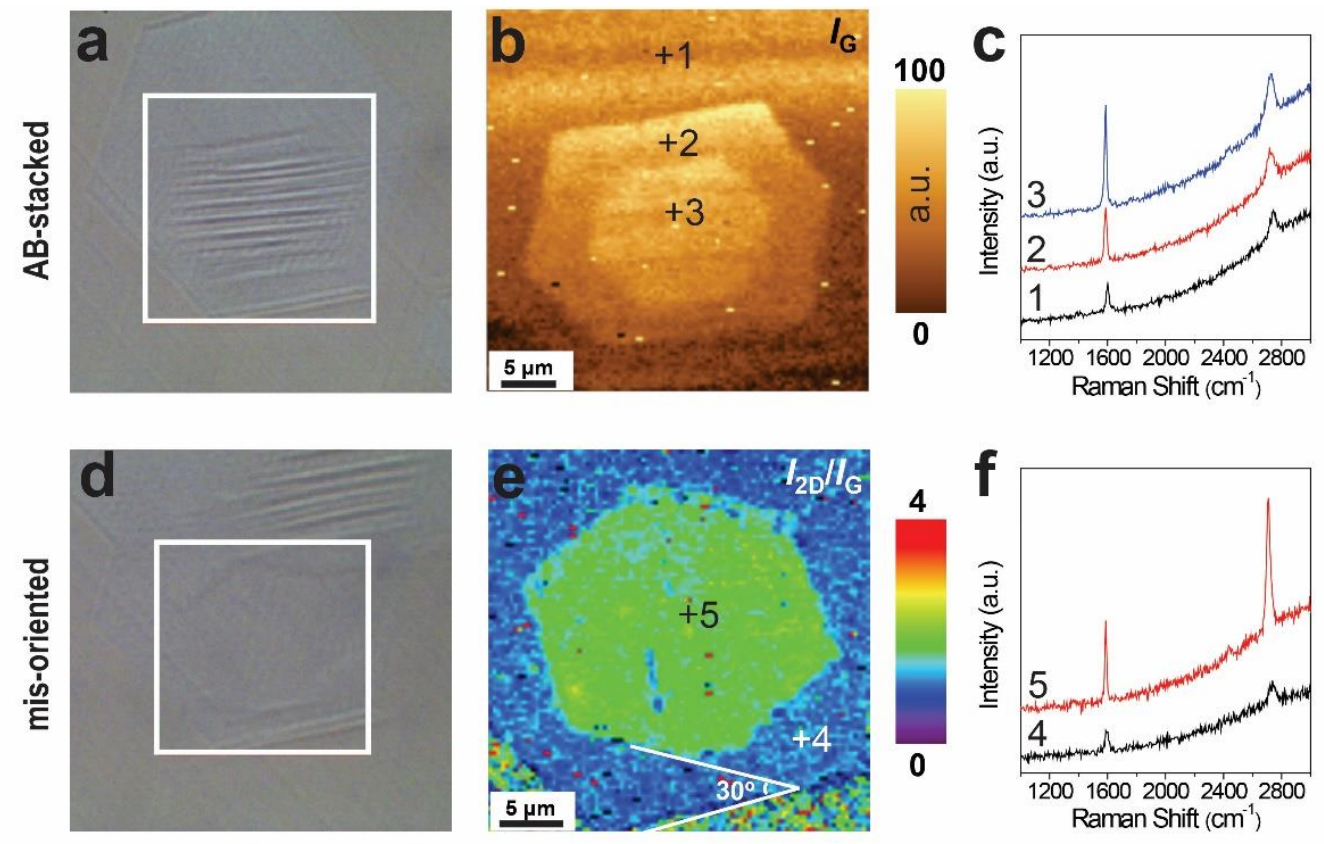

Figure S17. (a) Optical image (b), Raman G band intensity map and (c) Raman spectra recorded at the positions marked in (b) of the $\mathrm{AB} 2 \mathrm{~L} / 3 \mathrm{~L}$ island on $\mathrm{Cu}(111)$ before the reaction. (d) Optical image, (e) Raman $I_{2 \mathrm{D}} / I_{\mathrm{G}}$ map and (f) Raman spectra recorded at the positions marked in (e) of the $\mathrm{m} 2 \mathrm{~L}$ island on $\mathrm{Cu}(111)$ before the reaction.

We have also studied the functionalization of individual AB2L/3L (consisting of both $2 \mathrm{~L}$ and $3 \mathrm{~L}$ regions) and $\mathrm{m} 2 \mathrm{~L}$ graphene islands on $\mathrm{Cu}(111)$. Figure $\mathrm{S} 17 \mathrm{a}$ shows a hexagonal graphene island with a smaller hexagon inside. Higher step-bunching in the smaller hexagon and the parallel edges of the two hexagons suggest that the smaller region is few-layer graphene. The Raman G map (Figure S17b) and spectra (Figure S17c) clearly shows that this island contains $1 \mathrm{~L}, 2 \mathrm{~L}$ and $3 \mathrm{~L}$ graphene with AB-stacking in the few-layer region. In contrast, Figure S17d shows an island containing $1 \mathrm{~L}$ and $\mathrm{m} 2 \mathrm{~L}$ graphene regions. Figure S17e clearly shows the misoriented stacking as indicated 
by the characteristic $I_{2 \mathrm{D}} / I_{\mathrm{G}}$ ratio as well as the rotation angle $\left(30^{\circ}\right)$ between the two layers.
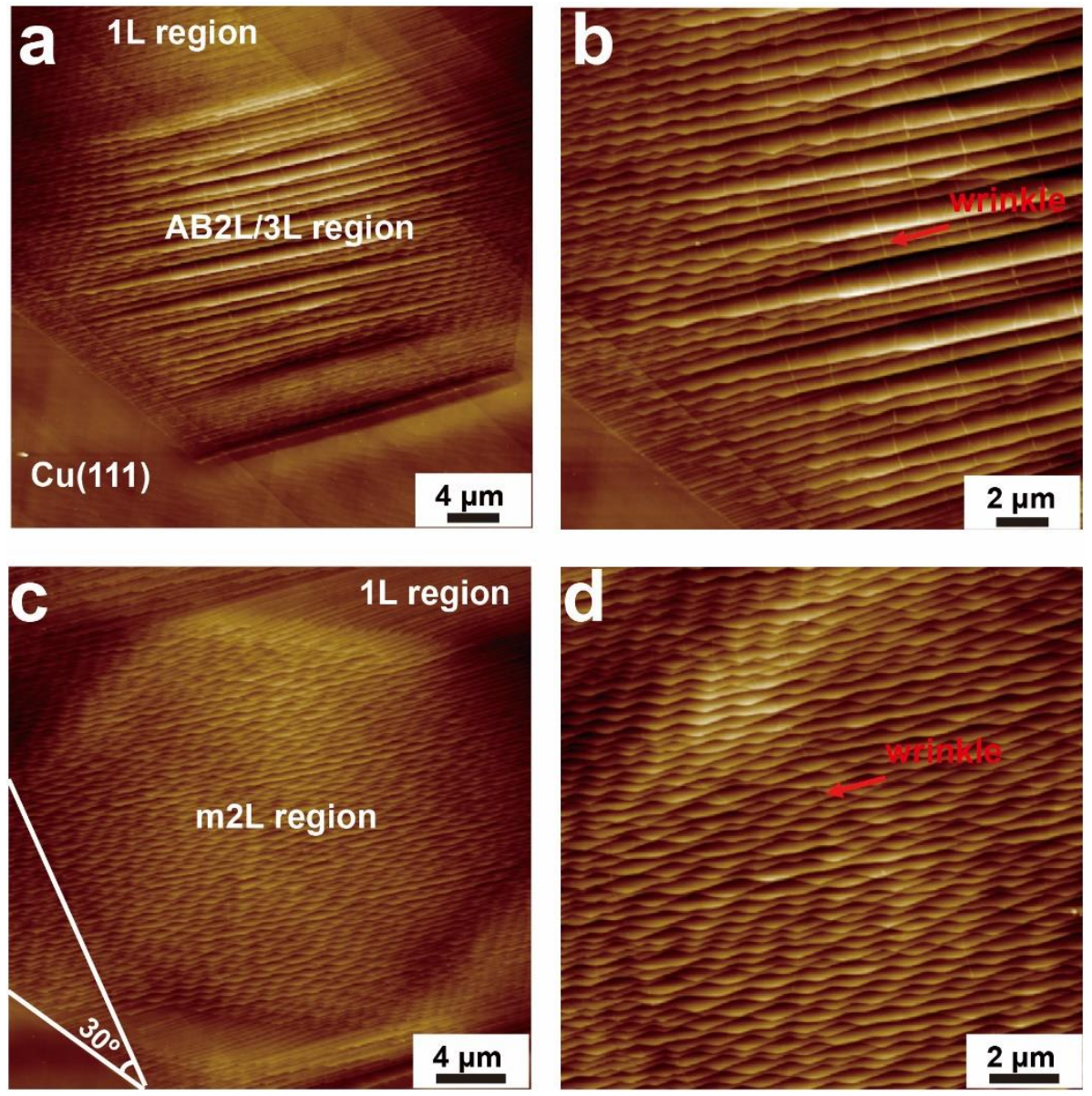

Figure S18. $(a, b)$ AFM height images of the AB2L/3L graphene island on $\mathrm{Cu}(111)$ shown in Figures S17a-c. (c, d) AFM height images of the m2L island on $\mathrm{Cu}(111)$ shown in Figures S17d-f.

AFM images of the same $\mathrm{AB} 2 \mathrm{~L} / 3 \mathrm{~L}$ island and $\mathrm{m} 2 \mathrm{~L}$ island on $\mathrm{Cu}(111)$ in Figure $\mathrm{S} 17$ are shown in Figure S18. In addition to similar AFM information given in Figure S15b, more wrinkles can be observed for the $\mathrm{AB} 2 \mathrm{~L} / 3 \mathrm{~L}$ island in the magnified $\mathrm{AFM}$ image. 
The formation of these wrinkles helps release the compressive strain in AB-stacked few-layer graphene.

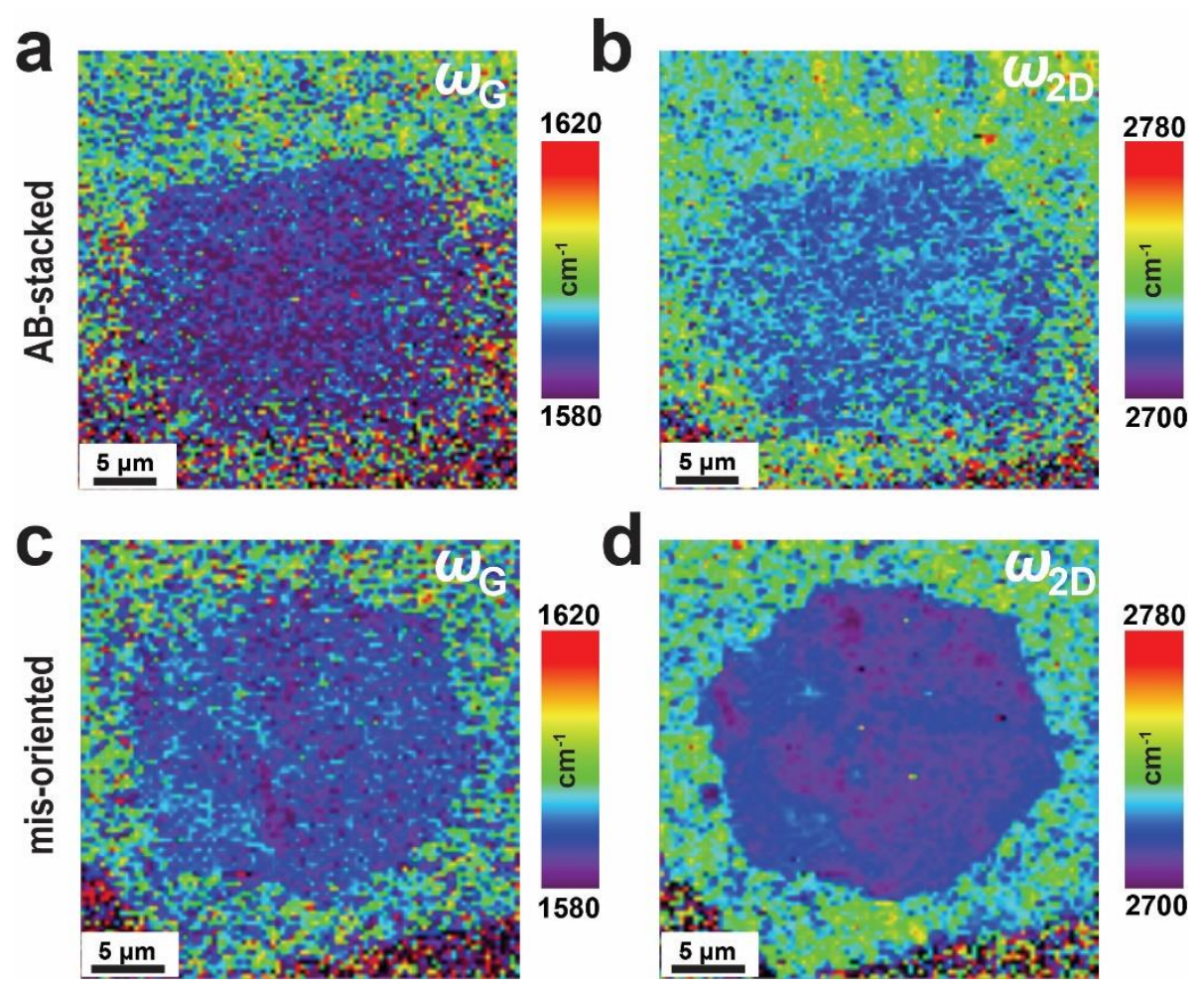

Figure S19. (a, b) Raman (a) $\omega_{\mathrm{G}}$ and (b) $\omega_{2 \mathrm{D}}$ maps of the $\mathrm{AB} 2 \mathrm{~L} / 3 \mathrm{~L}$ island on $\mathrm{Cu}(111)$ before functionalization. (c, d) Raman (c) $\omega_{\mathrm{G}}$ and (d) $\omega_{2 \mathrm{D}}$ maps of the $\mathrm{m} 2 \mathrm{~L}$ island on $\mathrm{Cu}(111)$ before functionalization.

Raman $\omega_{\mathrm{G}}$ and $\omega_{2 \mathrm{D}}$ maps (Figure S19) of the $\mathrm{AB} 2 \mathrm{~L} / 3 \mathrm{~L}$ and $\mathrm{m} 2 \mathrm{~L}$ islands show similar features as discussed in Figure S15. From the G band, one can estimate compressive strains of $-0.08 \%$ and $-0.11 \%$ for $\mathrm{AB} 2 \mathrm{~L} / 3 \mathrm{~L}$ and $\mathrm{m} 2 \mathrm{~L}$, respectively. The higher compression of $\mathrm{m} 2 \mathrm{~L}$ is in line with its fewer wrinkles than $\mathrm{AB} 2 \mathrm{~L} / 3 \mathrm{~L}$, as shown in Figure S18. 

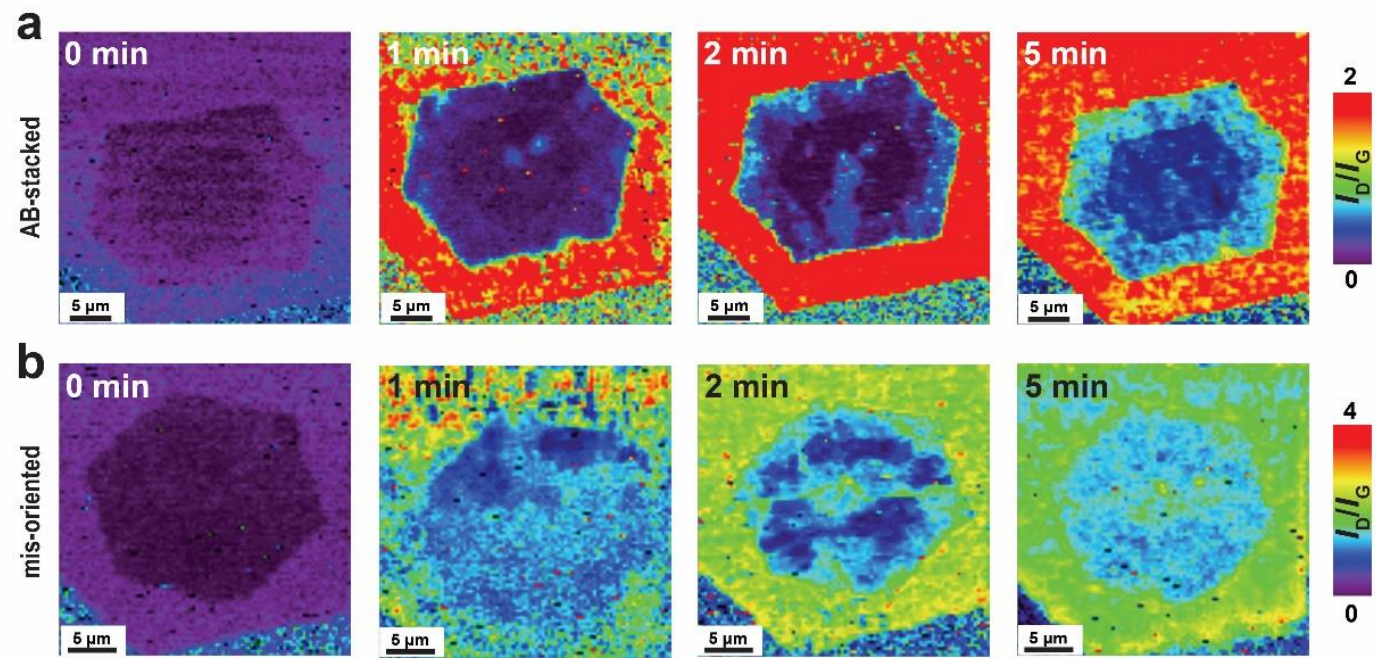

Figure $\mathrm{S} 20$. (a, b) $I_{\mathrm{D}} / I_{\mathrm{G}}$ maps of (a) the $\mathrm{AB} 2 \mathrm{~L} / 3 \mathrm{~L}$ island on $\mathrm{Cu}(111)$ and (b) the $\mathrm{m} 2 \mathrm{~L}$ island on $\mathrm{Cu}(111)$ before and after functionalization with different $t_{1}$ times for three runs.

Figure S20 shows the evolution of the reductive functionalization of the $\mathrm{AB} 2 \mathrm{~L} / 3 \mathrm{~L}$ and m2L islands (see Figures S17-S19) with the reaction time $t_{1}$. Similar to the discussion on Figure 6, m2L shows a higher degree of functionalization than $\mathrm{AB} 2 \mathrm{~L} / 3 \mathrm{~L}$ graphene. In addition, $3 \mathrm{~L}$ has a lower reactivity than $2 \mathrm{~L}$ graphene. 


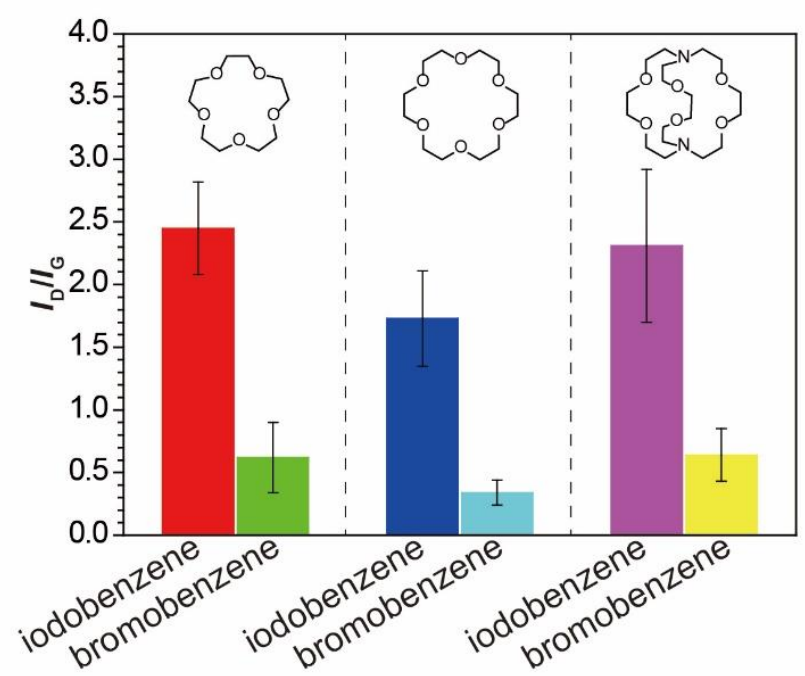

Figure $\mathrm{S} 21$. Raman $I_{\mathrm{D}} / I_{\mathrm{G}}$ distributions of functionalized $1 \mathrm{~L}$ islands on $\mathrm{Cu}(111)$ using 15 -crown5, 18-crown- 6 or cryptand-222. Reaction conditions: iodobenzene: $\left[C_{\mathrm{NaK}}\right]_{0}=0.02 \mathrm{M} ; t_{1}=5 \mathrm{~min}$; $t_{2}=5 \mathrm{~min} ; T=20^{\circ} \mathrm{C}$; bromobenzene: $\left[C_{N a K}\right]_{0}=0.02 \mathrm{M} ; t_{1}=10 \mathrm{~min} ; t_{2}=5 \mathrm{~min} ; T=20^{\circ} \mathrm{C}$.

We have also investigated the effect of macrocyclic ligands on the reductive functionalization of graphene on $\mathrm{Cu}(111)$. In principle, a macrocyclic compound capable of coordinating with an alkali cation should facilitate the dissolution of the alkali metal/alloy to form an alkalide solution. The coordination efficiency likely determines the dissolution rate and stability of the alkalide solution, which consequently alters the functionalization efficiency. In addition to 15 -crown-5, we prepared solutions that contained 18 -crown-6 or cryptand-222 along with $\mathrm{NaK}$ in THF, and then used these solutions to reduce the $1 \mathrm{~L}$ graphene islands on $\mathrm{Cu}(111)$ (see the experimental section). We found that while cryptand-222 resulted in a degree of functionalization that was close to that of 15-crown-5, 18-crown-6 led to a lower reactivity irrespective of whether iodobenzene or bromobenzene was used as the 
reagent (Figure S21). It has been reported that the sandwich-like $\left[\mathrm{K}(15 \text {-crown-5) }]^{+}\right.$ complex has a higher stability than the planar $\left[\mathrm{K}(18 \text {-crown-6) }]^{+}\right.$complex, which is attributed to the participation of more oxygen atoms in the coordination with potassium cations. ${ }^{25}$ On the other hand, cryptand-222 has a three-dimensional interior cavity, which may render it more selective than 18-crown-6. ${ }^{26}$ Regardless, 18-crown-6 exhibited the lowest reaction efficiency of the three ligands explored. Based on these results, we conclude that the degree of functionalization may be influenced by the macrocyclic additive.

\section{References}

(1) Yi, D.; Luo, D.; Wang, Z. J.; Dong, J. C.; Zhang, X.; Willinger, M. G.; Ruoff, R. S.; Ding, F. What Drives Metal-Surface Step Bunching in Graphene Chemical Vapor Deposition? Phys. Rev. Lett. 2018, 120, 246101.

(2) Hong, J.; Park, M. K.; Lee, E. J.; Lee, D.; Hwang, D. S.; Ryu, S. Origin of New Broad Raman D and G Peaks in Annealed Graphene. Sci. Rep. 2013, 3, 2700.

(3) Biswal, M.; Zhang, X.; Schilter, D.; Lee, T. K.; Hwang, D. Y.; Saxena, M.; Lee, S. H.; Chen, S. S.; Kwak, S. K.; Bielawski, C. W.; Bacsa, W. S.; Ruoff, R. S. Sodide and Organic Halides Effect Covalent Functionalization of Single-Layer and Bilayer Graphene. J. Am. Chem. Soc. 2017, 139, 4202-4210.

(4) Li, B. W.; Luo, D.; Zhu, L. Y.; Zhang, X.; Jin, S. H.; Huang, M.; Ding, F.; Ruoff, R. S. Orientation-Dependent Strain Relaxation and Chemical Functionalization of Graphene on a $\mathrm{Cu}(111)$ Foil. Adv. Mater. 2018, 30, 1706504.

(5) Sun, H.; Jin, Z.; Yang, C. W.; Akkermans, R. L. C.; Robertson, S. H.; Spenley, N. A.; Miller, S.; Todd, S. M. COMPASS II: extended coverage for polymer and drug-like molecule databases. J. Mol. Model. 2016, 22, 47. 
(6) Ewald, P. P. Die Berechnung optischer und elektrostatischer Gitterpotentiale. Ann. Phys. 1921, $369,253-287$.

(7) Tosi, M. P. Cohesion of Ionic Solids in the Born Model. Solid State Phys 1964, 16, 1-120.

(8) Berendsen, H. J. C.; Postma, J. P. M.; Vangunsteren, W. F.; Dinola, A.; Haak, J. R. MolecularDynamics with Coupling to an External Bath. J. Chem. Phys. 1984, 81, 3684-3690.

(9) Hirshfeld, F. L. Bonded-Atom Fragments for Describing Molecular Charge-Densities. Theor. Chim. Acta 1977, 44, 129-138.

(10) Delley, B. An All-Electron Numerical-Method for Solving the Local Density Functional for Polyatomic-Molecules. J. Chem. Phys. 1990, 92, 508-517.

(11) Delley, B. From molecules to solids with the DMol(3) approach. J. Chem. Phys. 2000, 113, 7756-7764

(12) Perdew, J. P.; Burke, K.; Ernzerhof, M. Generalized gradient approximation made simple. Phys. Rev. Lett. 1996, 77, 3865-3868.

(13) Grimme, S. Semiempirical GGA-type density functional constructed with a long-range dispersion correction. J. Comput. Chem. 2006, 27, 1787-1799.

(14) Delley, B. Hardness conserving semilocal pseudopotentials. Phys. Rev. B 2002, 66.

(15) Monkhorst, H. J.; Pack, J. D. Special Points for Brillouin-Zone Integrations. Phys. Rev. B 1976, $13,5188-5192$.

(16) Halgren, T. A.; Lipscomb, W. N. Synchronous-Transit Method for Determining Reaction Pathways and Locating Molecular Transition-States. Chem. Phys. Lett. 1977, 49, 225-232.

(17) Klamt, A.; Schuurmann, G. Cosmo - a New Approach to Dielectric Screening in Solvents with Explicit Expressions for the Screening Energy and Its Gradient. J. Chem. Soc. Perk. T 2 1993, 799-805.

(18) Park, J. Y.; Han, B. W.; Lee, I. H. Preparation of electrospun porous ethyl cellulose fiber by THF/DMAc binary solvent system. J. Ind. Eng. Chem. 2007, 13, 1002-1008.

(19) Ferrari, A. C.; Robertson, J. Interpretation of Raman spectra of disordered and amorphous carbon. Phys. Rev. B 2000, 61, 14095-14107. 
(20) Ferreira, E. H. M.; Moutinho, M. V. O.; Stavale, F.; Lucchese, M. M.; Capaz, R. B.; Achete, C. A.; Jorio, A. Evolution of the Raman spectra from single-, few-, and many-layer graphene with increasing disorder. Phys. Rev. B 2010, 82, 125429.

(21) Cancado, L. G.; Jorio, A.; Ferreira, E. H. M.; Stavale, F.; Achete, C. A.; Capaz, R. B.; Moutinho, M. V. O.; Lombardo, A.; Kulmala, T. S.; Ferrari, A. C. Quantifying Defects in Graphene via Raman Spectroscopy at Different Excitation Energies. Nano Lett 2011, 11, 31903196.

(22) Lucchese, M. M.; Stavale, F.; Ferreira, E. H. M.; Vilani, C.; Moutinho, M. V. O.; Capaz, R. B.; Achete, C. A.; Jorio, A. Quantifying ion-induced defects and Raman relaxation length in graphene. Carbon 2010, 48, 1592-1597.

(23) Ferrari, A. C.; Meyer, J. C.; Scardaci, V.; Casiraghi, C.; Lazzeri, M.; Mauri, F.; Piscanec, S.; Jiang, D.; Novoselov, K. S.; Roth, S.; Geim, A. K. Raman spectrum of graphene and graphene layers. Phys. Rev. Lett. 2006, 97, 187401.

(24) Kim, K.; Coh, S.; Tan, L. Z.; Regan, W.; Yuk, J. M.; Chatterjee, E.; Crommie, M. F.; Cohen, M. L.; Louie, S. G.; Zettl, A. Raman Spectroscopy Study of Rotated Double-Layer Graphene: Misorientation-Angle Dependence of Electronic Structure. Phys. Rev. Lett. 2012, 108, 246103.

(25) Grobelny, Z.; Stolarzewicz, A.; Sokol, M.; Grobelny, J.; Janeczek, H. Enhanced Stability of Potassium Solutions in Tetrahydrofuran Containing 15-Crown-5. J. Phys. Chem. 1992, 96, 5193-5196.

(26) Huang, R. H.; Faber, M. K.; Moeggenborg, K. J.; Ward, D. L.; Dye, J. L. Structure of $\mathrm{K}+($ Cryptand[2.2.2]) Electride and Evidence for Trapped Electron Pairs. Nature 1988, 331, 599-601. 